ISSN: 0514-7336

DOI: http://dx.doi.org/10.14201/zephyrus201983139163

\title{
UNA OFFICINA DEDICADA AL TRATAMIENTO, MANUFACTURA Y VENTA DE OBJETOS DE HUESO EN AUGUSTA EMERITA (MÉRIDA, BADAJOZ)
}

\section{An officina dedicated to the treatment, manufacture and sale of bone objects in Augusta Emerita (Mérida, Badajoz)}

\author{
Macarena Bustamante-Álvarez* y Cleia Detry** \\ * Dpto. de Prehistoria y Arqueología. Facultad de Filosofía y Letras-UGR. Campus Universitario de Cartuja. 18071 \\ Granada. Correo-e: mbustamante@ugr.es. ID ORCID: https://orcid.org/0000-0001-5988-6908 \\ ** Centro de Arqueologia UNIARQ. Faculdade de Letras-Univ. de Lisboa. Alameda da Universidade. 1600-214 \\ Lisboa (Portugal). Correo-e: cdetry@gmail.com. ID ORCID: https://orcid.org/0000-0002-5359-2500
}

Recepción: 19/11/2017; Revisión: 6/07/2018; Aceptación: 15/10/2018

\begin{abstract}
Resumen: Durante una excavación arqueológica enmarcada en el xx Curso de Arqueología del Consorcio de Mérida se intervinieron varias estancias del ala norte de la Casa del Mitreo. Una de esas habitaciones, excavada hace ańos, correspondía a una taberna con salida a la calle que bordeaba a esta domus en su lado norte. Las labores arqueológicas que hemos desarrollado han permitido constatar la planta completa de una instalación artesanal que asociamos a la manufactura y venta de objetos de hueso. En este trabajo presentamos las evidencias arquitectónicas y el resultado del análisis de los restos materiales recuperados tanto en las recientes como en las antiguas excavaciones. Además, se ha realizado un estudio arqueofaunístico de los objetos de hueso localizados, lo que ayuda a comprender el modus operandi de este artesanado, pero también a perfilar datos vinculados con las prácticas culinarias cárnicas en época romana. Dado que hasta ahora no se conocían instalaciones peninsulares de estas características creemos que puede considerarse un primer ejemplo en esta provincia romana.

Palabras clave: Lusitania; arquitectura doméstica romana; taberna; trabajo del hueso; arqueofauna.

Aвstract: During archaeological excavations carried out in the xx Course of Archaeology of the Consortium of Merida several rooms of the north wing of the Casa del Mitreo were uncovered. One of those rooms, excavated years ago, corresponded to a taberna with an exit to the street that bordered this domus on its north side.. The archaeological work we have carried out has allowed us to identify the complete plan of a handcrafted installation that we associate with the manufacture and sale of bone objects. In this work, in addition to presenting the architectural evidence, the remains recovered in both recent and ancient excavations are analyzed. In addition, we have also made an archaeofaunistic study of the found bone objects, which helps to understand the modus operandi of this craftspeople but also to outline data linked to meat culinary practices in Roman times. Given that, until now, no peninsular installations of these characteristics were known. We believe it can be considered a fisrt example in this Roman province.

Key words: Lusitania; Roman domestic building; taberna; bone handcraft; archaeofauna.
\end{abstract}

(C) Universidad de Salamanca

Zephyrus, LXXXIII, enero-junio 2019, 139-163 


\section{Introducción}

En el verano de 2017, con motivo del xx Curso de Verano organizado por el Consorcio de Mérida $^{1}$, se planteó la posibilidad de excavar - n. ${ }^{\circ}$ de intervención 3817- tres de las tabernae -a, b y c- posicionadas en el ala norte de la conocida como "Casa del Mitreo" (Fig. 1). De las tres, dos ya habían sido objeto de excavación arqueológica en decenios previos; sin embargo, dichas actuaciones

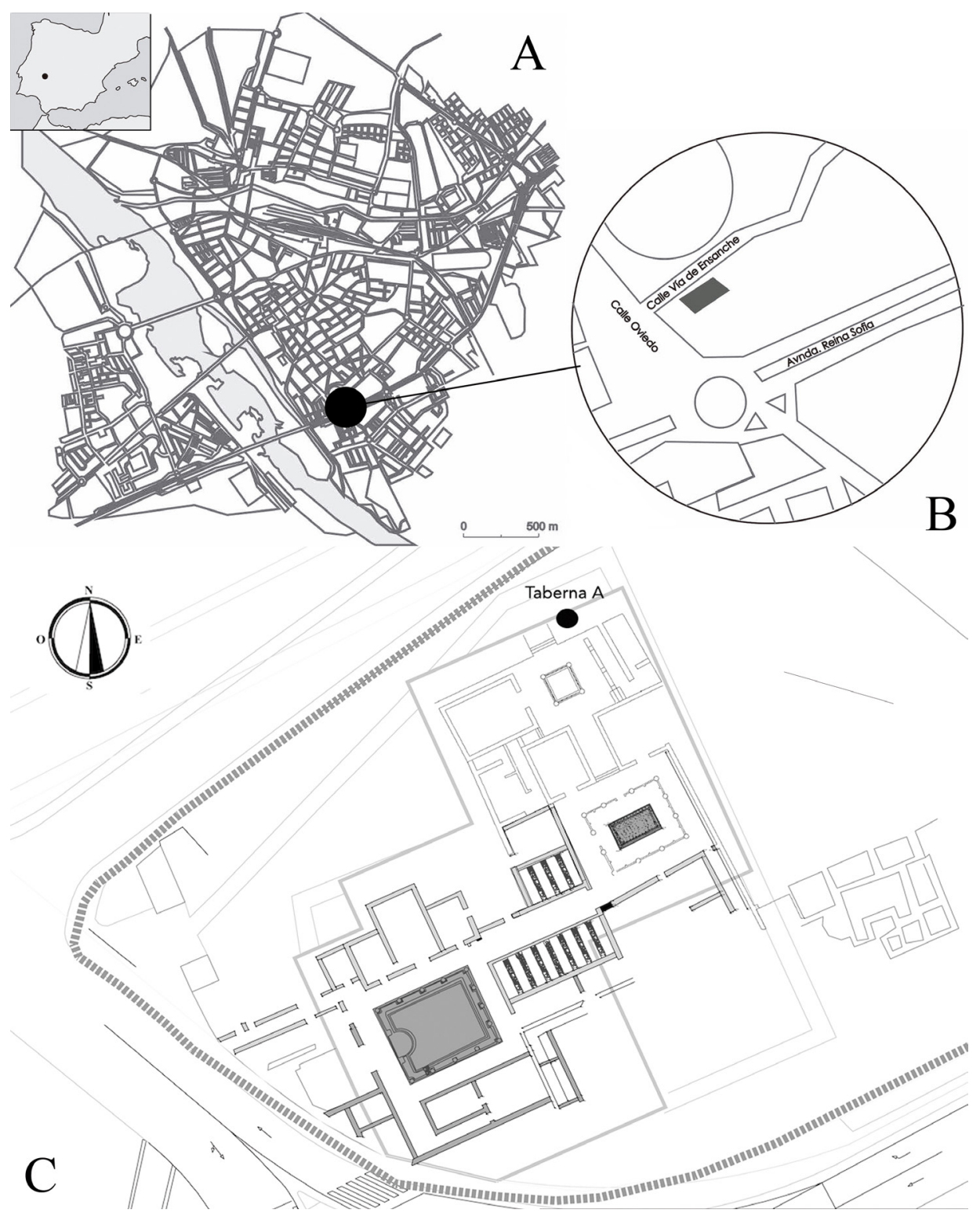

Fig. 1. Augusta Emerita: $A-B)$ su localización en la Península Ibérica y ubicación del solar en la trama urbana actual; C) plano de la Casa del Mitreo con indicación de la Taberna a (@) Consorcio de Mérida).

1 Agradecemos las facilidades prestadas al Consorcio de Mérida durante el desarrollo de la excavación, así como el posterior estudio (permiso de publicación y uso 713/2017).
De igual modo, extendemos el agradecimiento a J.-C. Béal, de la Univ. Lumière-Lyon 2, por sus interesantes aportaciones durante el desarrollo de este trabajo. 

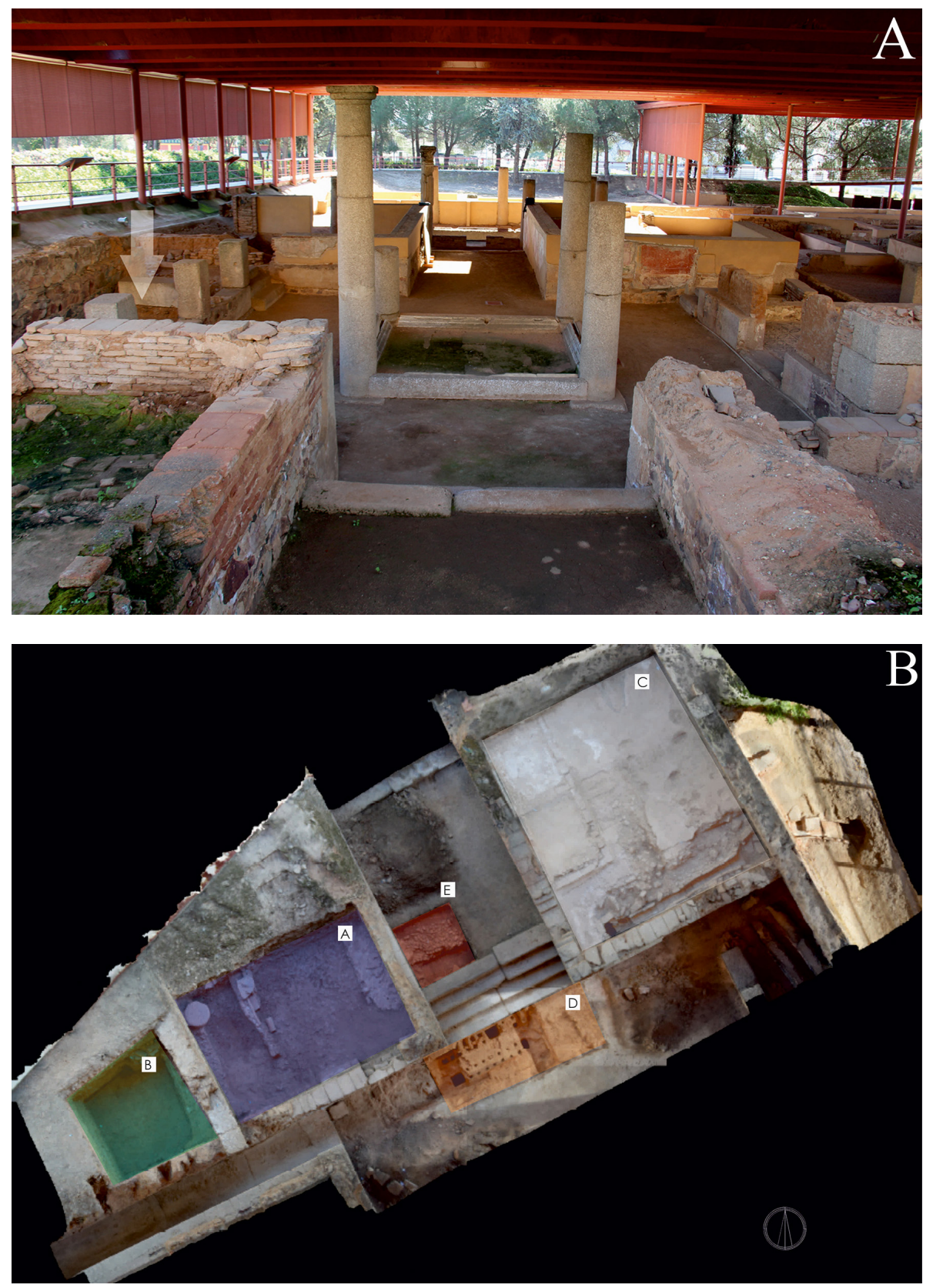

FIG. 2. Casa del Mitreo contemplada desde el $N: A$ ) vista del atrium con flecha indicando la taberna; $B$ ) ortofotografía de la zona intervenida con la indicación de cada sondeo: $a=$ sondeo Taberna $\mathrm{b} ; b=$ sondeo en la Taberna $\mathrm{c} ; c=$ Taberna a; $e=$ fauces; $d=$ sondeo en el atrium (@) Consorcio de Mérida). en 1994 durante las labores de adecuación e inserción de este espacio en el nuevo circuito de visitas y de cerramiento del solar. Esa excavación ya dejó a la vista un pavimento de opus signinum así como la impronta de dos piletas de escasa profundidad que indicaban el desarrollo indudable de una actividad artesanal en la zona.

En la intervención que hemos desarrollado en 2017 se ha podido liberar de sedimentos todo este espacio, analizar los materiales exhumados -tanto de esta actuación como de las previas- y realizar una lectura arqueológica de los restos arquitectónicos. A partir de todo ello se aporta una nueva interpretación de este espacio como taller y despacho de venta de objetos de hueso. Esta hipótesis, debido a los abundantes restos óseos trabajados, así como los desechos productivos localizados en el solar, ya había sido planteada previamente $^{2}$, pero no se había posicionado, de manera precisa, el lugar de esta actividad, ni se había planteado una hipótesis no habían sido concluidas ni dadas a conocer. De esas estancias la que nos interesa es la que hemos denominado Taberna c. Posicionada al $\mathrm{E}$ de las fauces de dicha casa, fue parcialmente intervenida
2 Gijón, M. E. (1994): Informe sobre la intervención arqueológica realizada en la Casa del Mitreo (Mérida), inédito y depositado en el Dpto. de Documentación del Consorcio de Mérida, Intervención 151. 
vinculando el modo productivo con las estructuras exhumadas. Por ello, esta es la primera vez que, al menos en suelo emeritense, se presenta una officina completa de tratamiento, producción y venta de objetos de hueso ${ }^{3}$.

Además de un análisis arquitectónico de los restos localizados en la taberna y de una clasificación tipológica de los objetos muebles hallados, este estudio se completa con un análisis arqueofaunístico de los restos óseos que permite trazar la cadena productiva de este particular artesanado. Nuestro estudio no ha sido enfocado a realizar una exégesis sobre la producción de objetos de hueso en la Antigüedad, ni en la capital lusitana ni en Hispania, ya que este tema ha sido abordado en trabajos anteriores, el más reciente de Rodríguez Martín (2014). Lo que aquí presentamos son las evidencias arquitectónicas de lo que consideramos una instalación única en la Península Ibérica (Fig. 2).

\section{La Casa del Mitreo. Breves apuntes}

En el verano de 1964 se iniciaron las labores de adecuación de un solar cercano a la actual plaza de toros, en el entorno del conocido como "Cerro de San Albín', para liberar este espacio de cara a la construcción de un centro de salud. Las labores de extracción de áridos, en todo momento, fueron supervisadas por E. García Sandoval ${ }^{4}$, responsable de las excavaciones de urgencia de la ciudad, quien desde el inicio, consciente de la posible riqueza que albergaba el sustrato, se posicionó a pie de obra registrando el proceso de excavación. En el marco de estas primeras intervenciones que, según su

3 Queremos recordar la sugerente hipótesis que ya ha sido planteada para Mérida, según la cual, en la colonia emeritense existiría un taller extramuros localizado en el actual solar donde se ubicaba el antiguo cuartel de artillería (Rodríguez Martín, 2014: 362). Allí se localizó un depósito asociado a epífisis que ha permitido plantear la posibilidad de que en ese lugar se realizara un primer tratamiento de las piezas y que la continuación de la cadena productiva se desarrollara en el interior de la ciudad.

4 García Sandoval, E. (1964): Diario de excavaciones del Cerro de "San Alvín", inédito y depositado en el MNAR. diario, se desarrollaron en el ángulo no de la domus, colindante con la actual c/ Oviedo, se produce la entrada en el MNAR de un lote compuesto por medio millar de piezas. Una parte considerable de ellas consistía en vasijas de paredes finas de producción local -algunas de ellas deformadas- $y$, en menor medida, una manufactura muy homogénea formal y decorativamente hablando de cerámica vidriada (Bustamante y Sabio, 2016). Estas evidencias ya apuntaban, indudablemente, al carácter artesanal de la zona.

A esta intervención hay que sumarle otras desarrolladas en el entorno y de las que, desgraciadamente, su proceso de documentación no ha sido el deseado. Destacamos las desarrolladas en septiembre-octubre de 1973 en la zona sur del complejo, más concretamente donde se ubican las termas, por R. Lequement (1978). Allí se identificaron evidencias de una zona artesanal vinculada con la manufactura de vidrio, así como restos del viario que en la actualidad se encuentran visibles e insertos en el circuito de visitas.

Además, tenemos constancia oral de la actuación en un momento impreciso de los años ochenta de un equipo francés abanderado por Étienne y Mayet que intervinieron en la zona norte de la casa coincidente con el sector que ahora hemos excavado5. De esta intervención no hemos podido localizar informe ni publicación alguna que ayude a su mejor esclarecimiento.

En los años noventa, debido al interés que suscitaba esta casa, se inicia un proyecto para su correcta cubrición y puesta en valor. Esta ingente obra arquitectónica precisaba de una serie de sondeos que ayudaran a liberar ciertos espacios por donde pasaba la pasarela y sobre los que se cimentaban los pilares que sustentaban la cubrición. Tenemos constancia, al menos, de dos intervenciones:

- La excavación desarrollada en 1993, bajo la dirección de M. J. Ferreira. De esta intervención hemos procedido a revisar los materiales localizados

5 Agradecemos la información oral proporcionada por F. G. Rodríguez sobre estas intervenciones, así como su apreciación personal sobre la instalación que ahora presentamos. 
en los almacenes del Consorcio de Mérida. Este análisis nos ha permitido plantear la posible ubicación de dichos sondeos, concretamente, en la zona de acceso a la domus, es decir, en las fauces. — La intervención realizada en 1994 y dirigida por M. E. Gijón ${ }^{6}$. De esta se conserva el correspondiente informe, por lo que hemos podido ubicar espacialmente los sondeos desarrollados, alguno de los cuales coincide con los planteados en esta excavación. De todos ellos interesan en este trabajo los Sondeos 3/1 y 3/3, que afectaron de lleno a la Taberna c. También hemos procedido al estudio de los materiales recuperados durante esta intervención que han ayudado a comprender mejor esta instalación artesanal.

Esta domus, a pesar de ser una de las mejor conservadas de Hispania, no ha sido hasta ahora objeto de un estudio global y minucioso. Las investigaciones, sobre todo, se han centrado en el análisis iconográfico de sus recursos decorativos: la pintura mural (Abad, 1982; Altieri, 2002) y los mosaicos (García de Sandoval, 1969; Blanco, 1978: 35; Quet, 1981; Fernández Galiano, 1989-1990 y 1996; Arce, 1996), que se fechan entre mediados del s. II y el iv d. C. Los estudios apuntan a que dicha vivienda podría haberse abandonado, al menos parcialmente, a causa de un posible incendio producido, bien en el s. III d. C. (Sánchez y Nodar, 1999), o bien ya avanzada la cuarta centuria (Sabio, 2012: 234-236).

6 También damos las gracias por las facilidades prestadas a la arqueóloga M. E. Gijón Gabriel, quien se ha personado en la excavación para aclarar algunas dudas que teníamos de dicha intervención.
Sobre el ala $\mathrm{N}$ de la casa no existe ningún estudio monográfico que trate la parte más comercial y pública de la misma, precisamente donde se posiciona la taberna que aquí estudiamos.

\section{Aspectos morfológicos y constructivos de la Taberna $c$ de la Casa del Mitreo}

La Taberna $c$ es una de las mejor conservadas y visibles desde el circuito actual de visitas de la casa. Se encuentra en el flanco E de las fauces, en la zona de acceso a la Casa del Mitreo. Conocemos su anchura, $5 \mathrm{~m}$ con orientación E-O, pero no su longitud que, con orientación $\mathrm{N}-\mathrm{S}$, queda camuflada bajo la pasarela de visita del complejo (Fig. 3). Esta taberna ya había sido intervenida previamente tanto en las excavaciones de los años ochenta como en la de 1994 -sondeo 3/3 en la parte n y 3/1 en el espacio s-. Por ello se decidió realizar esta limpieza. Hasta el momento, la única taberna que se podía percibir

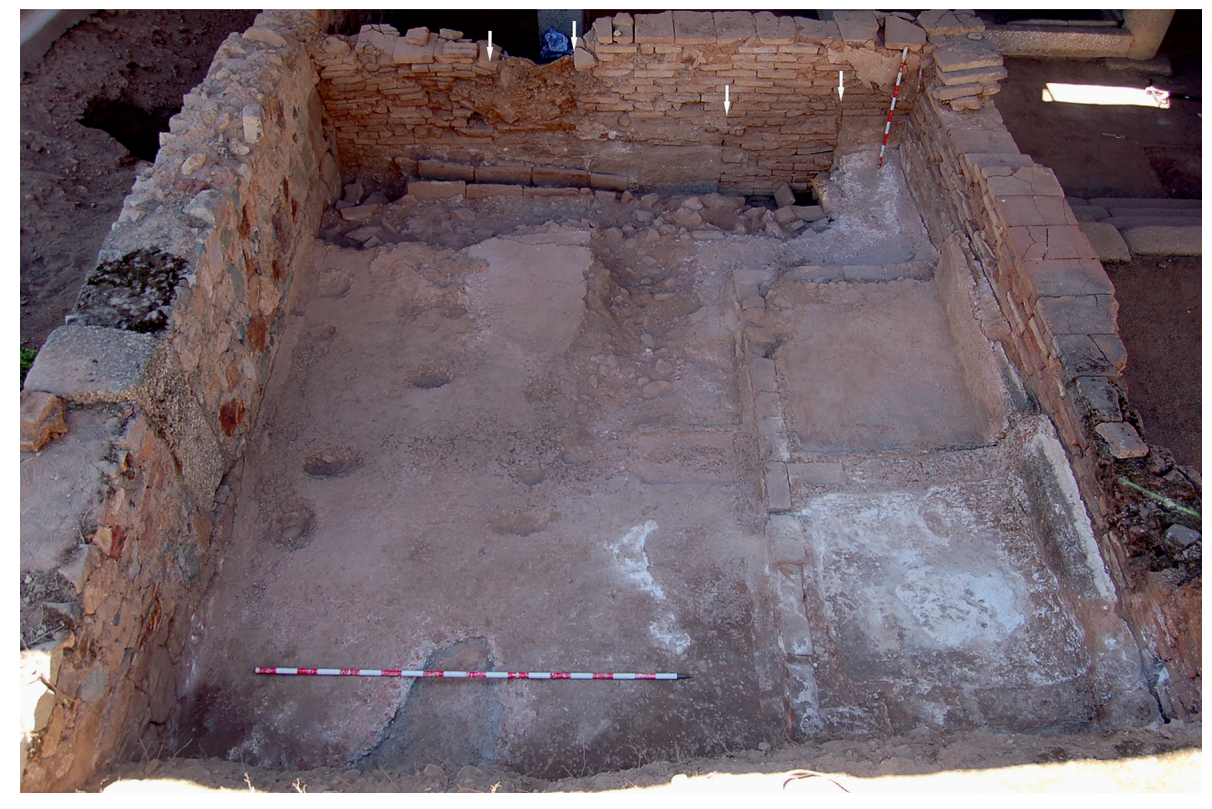

FIG. 3. Imagen de la taberna durante el proceso de intervención.

en integridad al haber sido excavada en anualidades previas era esta. Sin embargo, aún existía en su frente meridional, pegado al muro septentrional del atrio, un tacón de tierra que no había sido retirado 
en dichas excavaciones. Además, había que unirle que no existía una planimetría acorde a la entidad de los vestigios. Por ello se decidió actuar en dicho espacio.

$\mathrm{Al}$ igual que las otras tabernae posicionadas en este espacio, suponemos que tendría acceso público desde la calzada $\mathrm{N}$ que circunvalaba el complejo doméstico y estaría, en una primera fase, conectada con el atrium de la casa mediante un vano que fue tapiado en un segundo momento. De igual modo, tiene interés el hueco que se atisba desde el atrium y que podría responder a una ventana que habría intensificado, aún más, en algunos momentos, la relación de la taberna con la parte privada de la domus.

A continuación, iremos presentando cada una de las fases que se pudieron documentar durante esta intervención. A modo de sinopsis, se han documentado tres fases así como la amortización general del espacio, siendo la Fase in la que presenta mayor interés para la temática tratada aquí.

\subsection{Fase I: la construcción de la Taberna c}

Debido a la sólida pavimentación en opus signinum que cubría toda la estancia, no hemos podido aportar nuevos datos sobre los momentos iniciales de la Taberna $c$. Solo hemos analizado constructivamente los muros que cerraban el complejo y que, inicialmente, estuvieron presentes desde la construcción de la taberna. En esta primera fase existió una fuerte relación entre la domus y este espacio, como demuestran los vanos de puertas y de ventana que quedaron taponados en la Fase II.

A continuación, presentamos una ligera descripción de los mismos:

- Muro de cierre occidental -uc 025- de la Taberna $c$ que delimita las fauces en su lado $\mathrm{E}$. Con orientación N-S, presenta una longitud de 5,75 $\mathrm{m}$ ya que desaparece bajo la pasarela. Su anchura media es de $42 / 43 \mathrm{~cm}$ y está realizado con técnica constructiva mixta. En la esquina so se observa un bloque de granito bajo una lechada de cemento de época contemporánea que impide comprobar la existencia de otros bloques.
El basamento del muro está realizado con opus incertum de ripios con tamaño variable, prediseñados y colocados ordenadamente por tongadas. La parte superior está realizada con opus latericium de ladrillos tipo lydion -43 × 29 × 5 $\mathrm{cm}$-. La procedencia de los mampuestos es local y su coloración es rojiza, amarronada y grisácea. Desconocemos la zanja de cimentación ya que se posicionan diversas piletas al interior que anulan cualquier posibilidad de visualizar la taberna, el muro en integridad, así como el pavimento de opus signinum. En la zona exterior se apoya la escalera de acceso al atrium por lo que su construcción formó parte del proyecto inicial de obra.

- Muro de cierre E -UC 026- que delimita en su lado oriental la Taberna c. Presenta dirección $\mathrm{N}$-S y tiene 14,2 m de longitud x $57 \mathrm{~cm}$ de anchura y 1,3 m de altura. Se construyó con opus incertum de distinto tamaño y procedencia. En algunos puntos aparecen grandes bloques de granito que actúan como estípite a modo de opus africanum, aportando consistencia a la construcción. Este muro se apoya en un pavimento de opus signinum que se extiende por toda la $t a-$ berna y aparece obliterado por un canal de dudosa atribución y cronología que sale fuera del sondeo.

- Muro de cierre s -uc 027- que presenta dirección E-O. Tiene una longitud de $5,5 \mathrm{~m}$ y alcanza en algún punto hasta 1,8 m de altura. Su técnica constructiva es el opus incertum en su basamento más un alzado de ladrillos lydios. A $1 \mathrm{~m}$ de su límite oriental se identifica un vano, de 90 $\mathrm{cm}$ de anchura, que ha sido cegado con material latericio reutilizado. También se percibe una posible ventana, de unos $85 \mathrm{~cm}$ de anchura, que conectaría la taberna con el atrium y que ha sido taponada en época posterior. En la esquina más al o se percibe la presencia de una placa pictórica de unos 2,60 $\mathrm{m}$ de longitud que no permite ver las relaciones estratigráficas con el muro en cuestión. Dicho panel presenta coloración rojiza, azul y blanca. Por otra parte, en la zona inferior central del vano cegado antes mencionado se observa un orificio quizás para la salida de 
líquidos procedentes del sumidero de la Fase II localizado en el interior de la taberna.

El cerramiento $\mathrm{N}$ que tendría el acceso principal a la taberna no se ha localizado al encontrarse bajo la actual pasarela del circuito. Por ello, no podemos precisar si el cliente tendría acceso directo a este espacio o si, por el contrario, existiría un vestíbulo que separara la zona más pública de la privada, como se tiene constancia que sucedía en otros casos hispanos.

\subsection{Fase IIa: una officina $y$ taberna de manufactura de hueso}

Esta fase corresponde al segundo momento de ocupación de este espacio. Es ahora cuando el vano y el hueco de ventana se tapian independizando la taberna totalmente respecto de la casa. La officina inicial tendría el aspecto de una estancia pavimentada con opus signinum y con tres piletas de escasa profundidad recubiertas con el mismo tipo de opus y apoyadas en el muro o de la taberna.

Analizamos ahora cada uno de los elementos que estuvieron en uso durante la etapa activa de este espacio
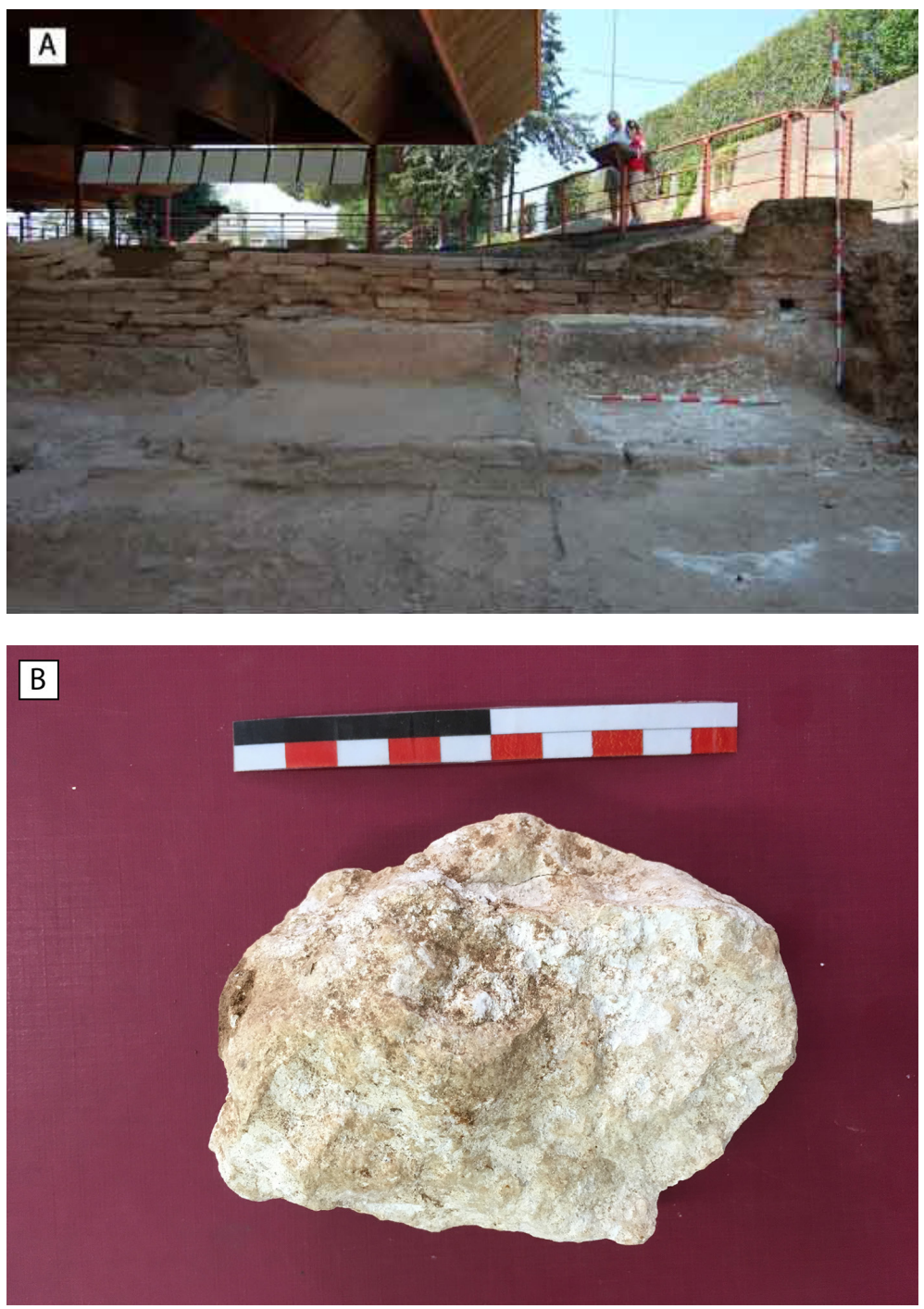

FIG. 4. A) Detalle de las piletas localizadas, con restos de cal en la n. ${ }^{\circ} 1 ;$ B) bola de cal localizada durante la intervención. como officina:

- Pileta 1: realizada en ladrillo y revestida de opus signinum, mide internamente $103 \mathrm{~cm}$ en sentido E-O x $125 \mathrm{~cm}$ en dirección N-S. En el muro de cierre -uC 025 - se observa una altura que alcanza hasta $53 \mathrm{~cm}$, paramento sobre el que se apoya y formaría un reborde de cierre superior hecho con opus signinum. En su fondo se constatan restos de cal viva de unos $4 / 5 \mathrm{~cm}$ de grosor (Fig. 4). Esto indica que en dicha pileta se utilizó este producto cuya interpretación comentaremos más adelante. Estratigráficamente la pileta se apoya sobre el muro de cierre o -UC 025y en su flanco e se le adosa el pavimento de signinum. Está construida en su lado o a partir de un muro maestro con $12 \mathrm{~cm}$ de anchura que se pierde bajo la pasarela. Este paramento es compartido con las piletas 2 y 3 .

- Pileta 2: realizada en ladrillo y revestida de opus signinum, presenta las siguientes dimensiones internas: $104 \mathrm{~cm}-\mathrm{E}-\mathrm{O}-$ por $126 \mathrm{~cm}-\mathrm{N}-\mathrm{S}-$. En el muro de cierre -uc 025- quedó señalada su altura hasta los $32 \mathrm{~cm}$ y también presenta restos 
de un reborde superior. En su fondo no se localizó ningún resto. Estratigráficamente se apoya sobre el muro de cierre Oeste -uc 025- y se le adosa en su flanco este suelo de signinum de la estancia. Está construida a partir de un muro maestro en su lado Oeste de una anchura $12 \mathrm{~cm}$ y se pierde bajo la pasarela. Este muro lo compartiría con la pileta 1 .

- Pileta 3: construida con opus signinum, se observa en el perfil $\mathrm{N}$ del sondeo, bajo la pasarela. De ella, únicamente, se pueden aportar datos sobre su anchura, $114 \mathrm{~cm}$ en dirección O-E.

Como hemos indicado, todo el espacio estaba pavimentado con opus signinum presentando una intensa pendiente hacia el s de la estancia. Se apoya en los muros UUCC 025 y 026 a partir de una media caña de sección semicircular que hace pensar en la presencia de elementos líquidos y semilíquidos en la estancia. También se apoya en las piletas con una similar solución. Por lo general, presenta un buen estado de preservación. La parte más central ya se encontraba visible en la intervención de 1994. Este pavimento, como veremos en el siguiente apartado, sufrió una serie de remodelaciones debido a la inserción de un canal en el frente s de la estancia que modificó sensiblemente el aspecto del lugar.

\subsection{Fase IIb: refacciones en el taller}

En un momento no preciso en el que el taller estaba funcionando se produjo una modificación del espacio en el lado meridional. Específicamente, se insertó un canal que solventaría los problemas de evacuación que se podrían haber generado en la taberna (Fig. 5). Esta actuación comprendía tanto un canal como un sumidero realizado en ladrillo. Se extiende de O-E por todo el lado sur de la taberna. Su dimensión total es 2,64 $\mathrm{m}$ de largo y una anchura interior de $2,55 \mathrm{~m}$. En la zona más al e se abre el canal a modo de bocina de unos $30 \mathrm{~cm}$ que daría prueba de que en este lugar se recogerían aguas procedentes de una posible altura superior como se atestigua por las cimentaciones de una posible pileta.
El canal presenta una pendiente hacia el o que permitiría conducir las aguas que caerían en el receptáculo anteriormente descrito hacia el so. Allí se posicionaría un posible desagüe cuadrangular cuyos lados N, E y o están hechos con una caja de ladrillo de unos 30 × $30 \mathrm{~cm}$ mientras que su lado $s$ aprovecha el muro de cierre de la taberna-Uc 027-. Este receptáculo iría en fase con el suelo de signinum, al menos, en una segunda etapa como se atestigua por el cuidado acabado en la unión entre el signinum y el borde del sumidero. Además, se observa una ligera pendiente de todo el signinum hacia dicha zona que hablaría de un redireccionamiento del subproducto trajinado. El módulo del ladrillo es de 30 × 12 × $5 \mathrm{~cm}$, es decir, presenta similares dimensiones a los usados en las piletas.

Para la construcción del canal, se planteó una gran zanja. Esta presentaba fisonomía rectangular y se encontraba ubicada en la zona $s$ del Sondeo c, paralela al muro uc 027 a excepción de la esquina so, donde se observa una depresión formada por la refacción del pavimento de opus signinum con una anchura media de 70/90 cm. Estratigráficamente, además, corta al opus signinum en la zona central y oriental de la estancia.

Esta segunda ocupación estaba amortizada por una capa de nivelación de tierra muy fina y pulverulenta con coloración amarillenta y puntos muy negruzcos. También aparecen bastantes ripios y restos de pintura mural muy deteriorados que aportaban una coloración muy grisácea a la capa. Los materiales allí localizados eran, sobre todo, restos óseos relacionados con la actividad allí desarrollada, así como cerámicas que aportan pocos datos desde el punto de vista cronológico al ser producciones locales comunes y no sistematizadas.

De igual modo, la amortización de la segunda fase se hacía patente en el relleno del canal, con un estrato de tierra de coloración rojiza con abundantes ripios que le proporcionaban una consistencia muy suelta. Su matriz era arenosa con algunos puntos de coloración negruzca y blanquecina.

\subsection{Fase III: el final del taller}

De esta fase de la Taberna $c$ se ha localizado un pavimento de ladrillos rectangulares posicionados 
exclusivamente en la esquina so del lugar cubriendo escasamente $1 \mathrm{~m}^{2}$. Este pavimento ya fue levantado parcialmente durante la intervención de 1994; sin embargo, no se había definido en amplitud su secuencia. Desde nuestro punto de vista debió ser más amplio y habría sido afectado por intervenciones más recientes allí desarrolladas. Se ubica sobre el estrato de tierra muy suelta antes descrita. Además, cabalga por encima de la Pileta 2 , a la que amortiza. Esto remite a una fase posterior a la de uso de las piletas, es decir, ya no estaríamos ante el taller previamente definido. Además, hay

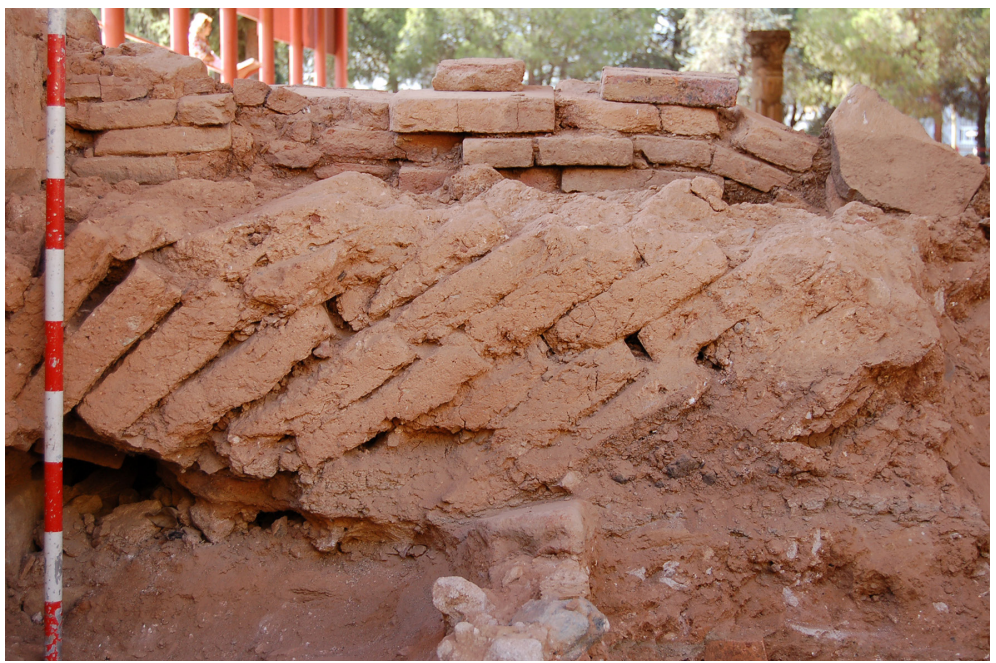

FIG. 5. Detalle del derrumbe de adobes ubicado en la esquina. que resaltar que los ladrillos aquí usados son los mismos que formaban parte de los muros de las piletas, lo que hablaría de su desmonte en momentos previos a la instalación de esta superficie.

\subsection{El final del espacio}

Como ya hemos advertido inicialmente, este espacio había sido ya intervenido en dos ocasiones (Fig. 5) y, por ello, gran parte de los estratos se ha perdido; sin embargo, en la esquina se de la taberna se dejó intencionadamente un tacón de tierra en el que se observaba un derrumbe de adobes de los muros adyacentes. Tras su preceptiva documentación procedimos a su levantamiento y eso ha permitido conocer más datos sobre la vida de este espacio. Sin embargo, esta zona estaba muy deteriorada por la afección de las aguas de lluvia procedentes de un segundo cuerpo. A pesar de ello, se ha podido documentar el módulo de los adobes allí usados -22 x 15 x $6 \mathrm{~cm}-$ y se ha procedido a la recogida puntual de materiales arqueológicos muy removidos al estar en la parte más superficial de la estancia. En estos paquetes se aprecia la convivencia tanto de cerámicas de época romana altoimperial -paredes finas locales tipo Mayet XxxviI, XLIV o LIII- como de época bajoimperial -fragmentos tipo Hayes 50 en ARSW-C-. Este estrato estaba cubierto por una unidad con

amplios detritos urbanos fruto de las actuaciones contemporáneas que podrían haber contaminado los estratos inferiores. Destaca la presencia de más de una decena de fragmentos de acus y desbastes de hueso que, sin lugar a dudas, ya inducían a la propuesta funcional que defendemos para este espacio.

A pesar del abundante registro mueble hallado, las condiciones estratigráficas, con remociones claras y un fuerte componente residual e intrusivo, no permiten precisiones cronológicas fiables. Creemos de interés la dinámica de formación del estrato con un derrumbe brusco y puntual de los adobes de las paredes colindantes que marcaría un hiato de amortización del espacio y no un lento abandono progresivo.

\section{Un taller de manufactura de hueso}

Tras el análisis de las fases identificadas durante el proceso de intervención planteamos que, durante la que hemos denominado Fase II, se estableció una officina para el tratamiento, manufactura y venta de objetos de hueso. Fundamentalmente, los indicios que hacen pensar en esta función son dos:

a) las evidencias arquitectónicas y

b) los objetos muebles y ecofactos localizados en la taberna y en sus inmediaciones. 


\subsection{Las evidencias arquitectónicas}

El carácter artesanal de este espacio parece innegable. Por un lado, está su posicionamiento en la casa, en una taberna con salida directa hacia la calle y, por otro, la presencia de piletas y de una robusta pavimentación en opus signinum. Es una habitación de reducidas dimensiones en la que, en su flanco occidental, pegado al muro de cierre de las fauces, se adosan tres piletas realizadas en opus mixtum -incertum y lateritium - y revestidas de opus signinum. A pesar de su estado de conservación, muy arrasado por actuaciones posteriores, creemos que, a juzgar por las adherencias en su interior, serían tres piletas independientes, no interconectadas, usadas en la cadena productiva. Recordamos que de las tres, únicamente dos, las posicionadas más al s y que no se vieron afectadas por la pasarela del circuito de visitas, pueden ser valoradas íntegramente. En el planteamiento de estas piletas, que comparten en algunos casos muros maestros, parece observarse un proyecto de obra único. Sus dimensiones medias son $103 / 104 \mathrm{~cm}$ en sentido E-O x 125/126 cm en sentido N-S y una altura de $32 / 33 \mathrm{~cm}$. Esto permite calcular una capacidad de unos 2801 teniendo en cuenta que no se llenarían hasta arriba, sino que se mantendría una distancia de unos $10 \mathrm{~cm}$ hasta el borde para evitar que la sustancia rebosara. Además del líquido se introducirían las piezas a tratar, lo que también reduciría sensiblemente esta capacidad total.

El flanco E está exento de cualquier evidencia de vestigios arquitectónicos fijos. Únicamente se observa un pavimento de opus signinum que se extendería por toda la estancia con cierta pendiente hacia el so, donde se documenta, para un segundo momento, una fuerte depresión revestida de opus signinum que conduciría a un sumidero conectado con un canal latericio. Ese canal, con una ligera pendiente E-O, permitiría recoger, gracias a una pseudopileta abocinada posicionada en su extremo oriental, los líquidos procedentes de un segundo cuerpo que, posiblemente, se usarían en el desarrollo de la manufactura.

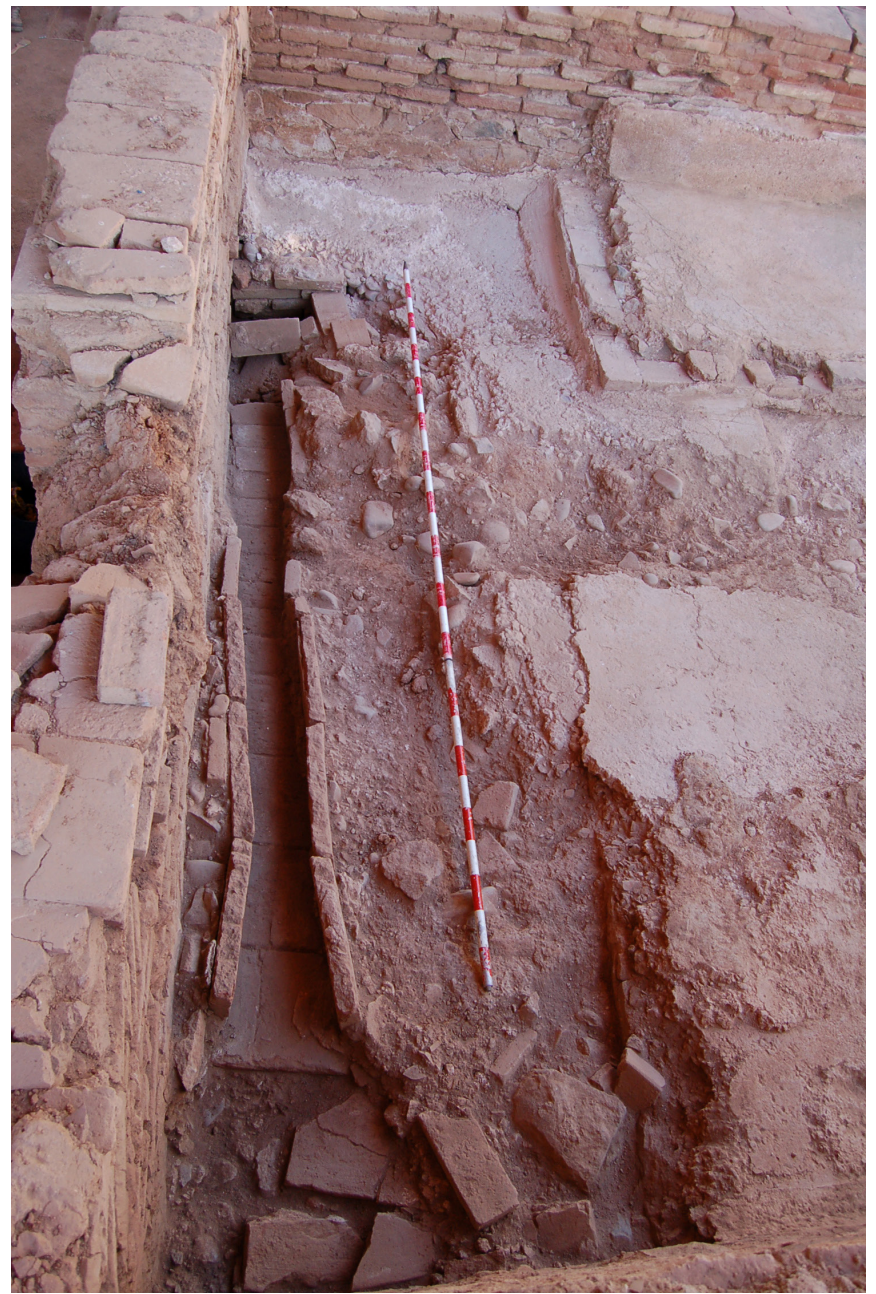

FIG. 6. Canal localizado en la zona meridional de la taberna.

Teniendo en cuenta estos elementos, ¿qué actividades artesanales podrían haberse desarrollado en este espacio? Creemos que estamos ante un taller para el tratamiento, talla y venta de hueso. Hasta el momento, las evidencias que conocíamos del trabajo del hueso en la Península Ibérica se reducían, fundamentalmente, a la materia prima -arqueofauna-, sus descartes o bien objetos trabajados o en proceso de elaboración. Sin embargo, no se habían llegado a detectar espacios que pudieran asociarse específicamente a este tipo de trabajo ${ }^{7}$. Es decir, no se había analizado hasta ahora una estructura arquitectónica que pudiera responder a este tipo de

Para más datos sobre los vestigios localizados en la Península Ibérica cf. Rodríguez Martín, 2014. 
instalación y esclareciera su cadena de producción. En este trabajo damos a conocer una instalación que interpretamos, tanto por su análisis arquitectónico, como por la revisión de los materiales muebles, como una officina dedicada a la manufactura y venta de productos hechos en hueso.

Hasta el momento, instalaciones de estas características no habían sido documentadas en otros puntos de la Península Ibérica. Sin embargo, contextos como los identificados en Francia prueban la existencia de una industria ampliamente difundida, pero con pocas evidencias vinculadas a los modos productivos (Béal, 1983b; Rodríguez Martín, 2014). En Champallement (Devauges, 1975) y en Alésia (Sautot, 1978: 30-31) hay enclaves de este tipo. La tienda-taller de Alésia se abría a una de las calles comerciales en un barrio artesanal. En su interior se identificó una mesa de piedra usada como superficie de trabajo y mostrador, así como una letrina. Cronológicamente, esa instalación corresponde a un horizonte fechable entre Trajano/ Adriano y el 270 d. C.; es decir, la datación propuesta es similar a la que hacemos para el taller emeritense. En el caso francés, la ausencia de piletas asociadas y de espacios destinados a la preparación de la materia prima, creemos que podría deberse a la recepción de los huesos ya tratados para ser trabajados allí.

Con la intención de asociar cada uno de los elementos localizados a una función comenzamos con un análisis detallado empezando por las piletas. El proceso por el cual el cadáver de un animal pasa a convertirse en materia prima presta a ser trabajada es lento. En principio, es necesario mantener el contacto con una carnicería que proporciones osamentas de animales una vez que hayan sido despiezados. Para algunos autores tendría interés la presencia de estas instalaciones cerca de los talleres y la convivencia con otros con similar modo productivo, como las carpinterías (Béal, 1983a: 15). En nuestro caso tampoco descartamos la posibilidad de que la materia prima fuera aportada, al menos parcialmente, por los desechos del consumo cárnico de la propia domus, con entidad suficiente para tener un importante excedente de este tipo de materiales.
En un segundo momento habría que trasladar los restos óseos al correspondiente taller. Una vez transportada la materia prima a la officina habría que cerciorarse de que los restos cárnicos desaparecieran mediante algún producto que corroyera e, incluso, desinfectase el hueso, por ejemplo, la cal viva. Cuando el material óseo se encontraba totalmente limpio había que reblandecer el producto y, en ocasiones, modificarlo cromáticamente.

Sobre todos los pasos de esta manufactura y, en general, de la industria vinculada al hueso, son muy pocas las evidencias textuales que tenemos. Únicamente contamos un pasaje de Plutarco (An vitiositas ad infelicitatem sufficia, cap. 4), en el que se compara cómo se trabajaría el hueso con los vicios humanos "... pues como un hilo sierra a través del hueso que ha sido empapado en cenizas y vinagre, y como los hombres doblan el marfil cuando se ha hecho suave y flexible por la cerveza"... A pesar de la parquedad en los detalles estas palabras resultan de interés. En primer lugar, porque en un mismo párrafo se refieren al trabajo del hueso y al del marfil, lo que podría inducir a pensar que ambos materiales se vinculan con un mismo grupo gremial y que su manufactura sería muy similar. En segundo lugar, este texto refiere algunas partes del procesado del hueso como son el embadurnado en cenizas y vinagre para su reblandecimiento y el corte mediante un hilo-sierra. Para el caso concreto del marfil describe la suavidad y flexibilidad que le aporta la aplicación de la cerveza.

Esto pone de manifiesto la necesidad de aplicar a los huesos recién descarnados productos que permitan eliminar cualquier resto cárnico y, además, les confieran nuevas características mediante el reblandecimiento o el cambio cromático. Para ello era necesario disponer de contenedores donde desarrollar estas actividades y las piletas fueron los lugares idóneos para estos procesos. Recordemos que dentro de la Taberna $c$ teníamos dos completas y otra más que se perdía bajo los perfiles de este espacio. El tamaño de las mismas, a nuestro juicio, es muy reducido como para su posible vinculación con otro tipo de actividades como las desarrolladas en las $f u$ llonicae, infectoriae o perfumerías. Además, el hecho 

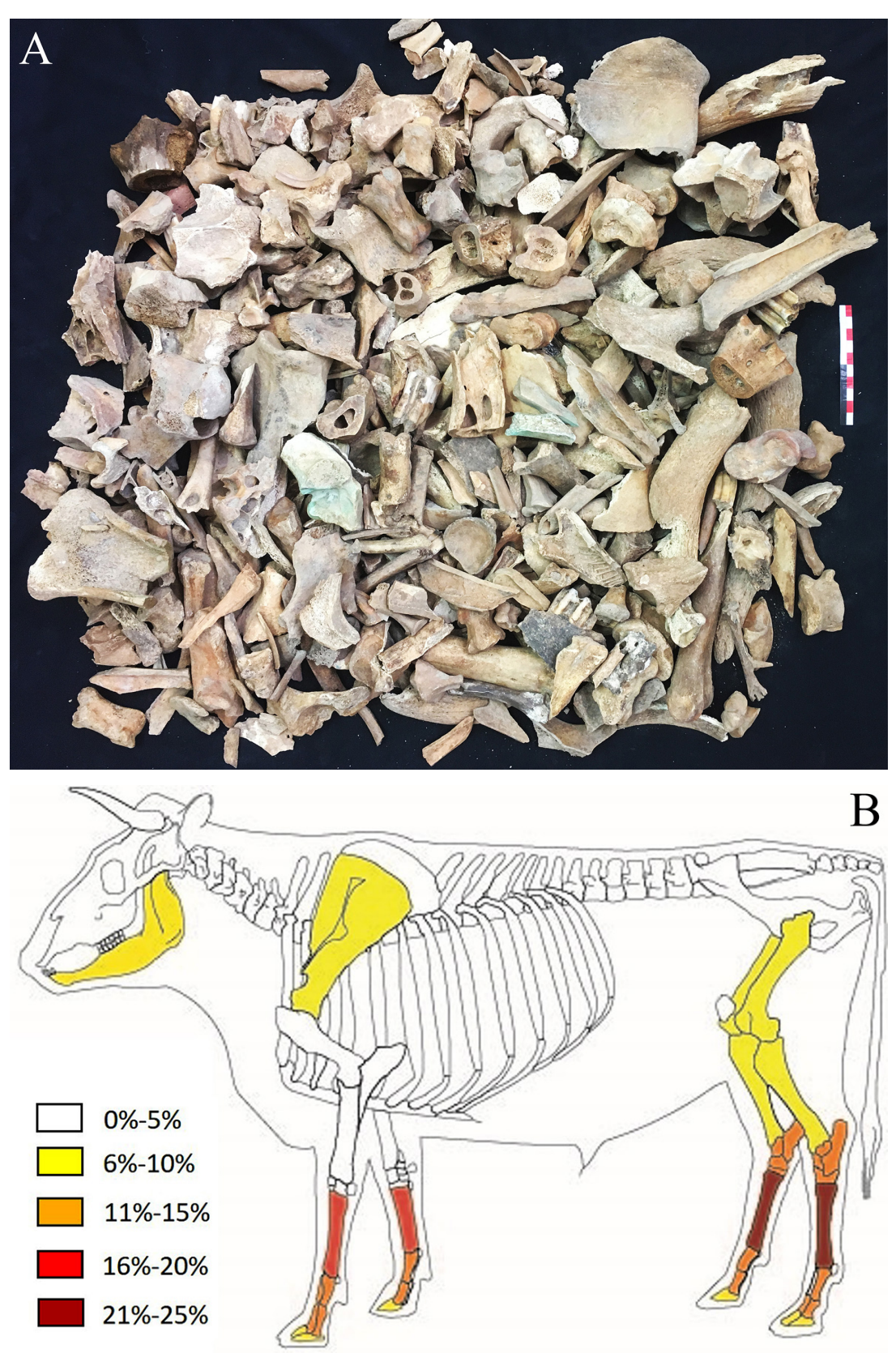

Fig. 7. A) Restos de arqueofauna localizados en la taberna; B) indicación de los principales puntos de extracción de los restos de bóvidos documentados. mediante cal viva y no por cocción, ya ha sido puesta de relieve (Krzyszkowska, 1990: 71; Rodríguez Martín, 2014: 362).

Desde nuestra perspectiva, cada una de las piletas habría estado destinada a la limpieza, desinfección y reblandecimiento de los huesos. De las tres, esa función de limpieza es más clara en la que presentaba restos de cal viva en el fondo; en la otra, debido a que ha estado a la intemperie durante mucho tiempo, no se perciben macroscópicamente restos. El otro paso por el que pasaría el material óseo sería un baño en vinagre o en leche en mal estado para reblandecer la materia prima (Macgregor, 1985: 63).

Además, la presencia de un pavimento de opus signinum indicaría el trabajo en la zona con sustancias líquidas (Figs. $7 b$ y 8 ), no solo vinagre sino también agua para limpiar los residuos adheridos a los huesos. Además, existiría una zona diáfana donde los artesanos podrían realizar el proceso de secado, corte y el trabajo específico de cada una de las piezas que luego serán presentadas.

\subsection{Las evidencias materiales}

Es evidente que, puesto que de que estuviera una de las piletas impregnada por una gruesa capa de cal viva en el fondo, uno de los posibles desinfectantes usados en estos procesos, convierte la propuesta del taller de hueso en una opción aceptable. La necesidad de este tipo de cubetas, siempre y cuando se optara por la limpieza se trata de una intervención desarrollada parcialmente y cuyo final ocupacional no ha sido fruto de un hito fatalista -como es el caso de las ciudades vesubianas-, el registro se encuentra alterado por los procesos postdeposicionales. Ante esta situación, no nos hemos limitado a estudiar los materiales 
exhumados en la última campaña, sino también los que fueron localizados en intervenciones previas y que estaban depositados en el Consorcio de Mérida. Hemos conseguido reunir restos de arqueofauna sin trabajar, trabajada, desbastes del proceso de manufactura, así como piezas ya concluidas.

\subsubsection{Arqueofauna}

Durante el desarrollo de la intervención, se observó cómo la taberna ubicada en el otro lado de las fauces había sido usada como terrera. En ella se pudo recuperar una gran cantidad de restos óseos faunísticos procedentes de la excavación de la $T a$ berna c. Esto se debe a que en las intervenciones anteriores la metodología arqueológica no prestaba interés a la recogida de los restos faunísticos. Sin embargo, los materiales de esa terrera nos han permitido completar el registro y proceder a su análisis biológico (Fig. 7a).

Siempre que sus características lo han permitido, los restos recuperados en este espacio han sido analizados e identificados taxonómica y morfológicamente. El registro del conjunto faunístico se ha realizado siguiendo los principios definidos por Davis (1992) y las medidas osteométricas se han obtenido a partir de los parámetros de Driesch (1976). También se han analizado tipos de fracturas, marcas de corte y trazas de agentes no antrópicos. En ningún caso los restos óseos presentaban marcas de fuego.

El conjunto, a pesar de ser reducido, proporciona datos interesantes (Figs. 7 b y 8 ). Se ha registrado un total de 178 piezas atribuibles a mamíferos, de los que 147 son huesos y 31 dientes. Se suman 7 huesos de aves. No se registran restos de moluscos, algo lógico dada la situación interior de Mérida.

El mamífero más abundante es el ganado bovino -Bos taurus- con 63 huesos y dientes. Los elementos de este grupo son también los que representan más evidencias de haber sido serrados con un instrumento metálico generando fracturas regulares y transversales en su diáfisis. Su objetivo sería aprovechar las diáfisis de los huesos largos para elaborar objetos de cierta longitud, principalmente alfileres

(C) Universidad de Salamanca y agujas. El hecho de tener documentada toda la cadena operativa en esta oficina, con las diferentes fases de trabajo de las diáfisis, refuerza la hipótesis de que se trata de un taller dedicado a este oficio.

Los huesos más frecuentemente serrados son metacarpos y metatarsos, aunque también se han registrado una tibia y un fémur con similares características. Los metápodos son particularmente útiles para este fin ya que son huesos largos y rectos, perfectos para elaborar agujas grandes, frente a los restantes huesos que están más curvados. El hecho de que los huesos de vaca más frecuentes sean los metápodos, seguidos por las tibias, muestran que el interés en estas partes de su esqueleto ultrapasa la práctica alimentaria. Además, estos huesos presentan poca carne adherida, por lo que el aprovechamiento óseo de este material es su principal finalidad.

Los caprinos son el segundo conjunto más abundante con 55 piezas identificadas. La subfamilia Caprinae corresponde a dos especies: la oveja -Ovis capra-y la cabra-Capra hircus-, muy difíciles de diferenciar a nivel osteológico. Apenas contamos con 1 diente -dp4- y dos astrágalos que pertenecen a ovejas. También se han registrado 7 cuernos de oveja. Muy probablemente el material que realmente se quiso aprovechar de estos elementos fuera la "camada" de origen queratinoso que cubría el cuerno del animal vivo. Este material constituía un elemento usado en utensilios ya que posee bastante resistencia y maleabilidad. Tras su tallado, podría usarse para fabricar piezas de menaje del hogar -copas-, adornos textiles -botones- o elementos de aderezo personal -pendientes-. Incluso se ha atestiguado que, cortado en finas capas translúcidas, podía servir como vidrio para lámparas (Konczewska, 2011; Rijkelijkhuizen, 2013).

Los suidos-Sus sp., cerdo o jabalí- son el tercer conjunto más representado entre los restos óseos, con 9 dientes y 14 huesos. De ellos, casi la mitad pertenecen a animales jóvenes. Ninguno de los restos tiene tamaño comparable a los del jabalí. Estos huesos carecen de marcas de corte o evidencias de haber sido serrados. Parece que este tipo de animal únicamente fue usado para consumo doméstico. 


\begin{tabular}{|c|c|c|c|c|c|c|c|c|c|}
\hline Restos óseos & Fusión & B & $\mathrm{o} / \mathrm{C}$ & $s$ & CEE & EQ & ORC & CAC & CAM \\
\hline \multicolumn{10}{|l|}{ cráneo } \\
\hline cuernos & & & 7 Ovis & & & & & & \\
\hline mandíbulas & & 1 & 4 & 2 & & & 2 & & \\
\hline \multicolumn{10}{|l|}{ dientes } \\
\hline incisivo & & 1 & & 3 & & 1 & & & \\
\hline canino & & & & 2 & & & & & \\
\hline dec. premolar 4 & & & 1 Ovis & $(1)$ & & & & & \\
\hline premolar 2 & & & $(1)$ & & & & & & \\
\hline premolar 3 & & 1 & $(2)$ & & & & & & \\
\hline premolar 4 & & & $(2)$ & & & & & & \\
\hline molar 1 & & & $1(3)$ & $(2)$ & & & & & \\
\hline molar 2 & & & $(3)$ & (1) & & & & & \\
\hline molar 3 & & $1(1)$ & $(2)$ & & & & & & \\
\hline molar/premolar & & & & & & 2 & & & \\
\hline \multicolumn{10}{|c|}{ esqueleto apendicular } \\
\hline escápula & $\mathrm{F}$ & 1 & & & & 1 & 3 & & \\
\hline \multirow{4}{*}{ húmero } & $\mathrm{F}$ & & & 1 & & & 4 & 1 & \\
\hline & UM & & 1 & & & & & & \\
\hline & UM & & 1 & & & 1 & & & \\
\hline & UE & & & & & & & & \\
\hline \multirow{3}{*}{ radio } & $\mathrm{F}$ & & & & & 1 & & & \\
\hline & UM & & 3 & & & & & & \\
\hline & $\mathrm{UE}$ & & & 1 & & & & & \\
\hline \multirow{3}{*}{ metacarpo } & $\mathrm{F}$ & 5 & 2 & & 1 & 1 & & & \\
\hline & $\mathrm{FV}$ & & 1 & & & & & & \\
\hline & UM & & & 1 & & & & & \\
\hline \multirow{2}{*}{ pelvis } & $\mathrm{F}$ & & 3 & 1 & & 1 & 2 & & \\
\hline & $\mathrm{I}$ & & & 1 & & & & & \\
\hline \multirow{2}{*}{ fémur } & $\mathrm{F}$ & 2 & 1 & & & & 2 & & \\
\hline & $\mathrm{FV}$ & & 1 & & & & 2 & & \\
\hline \multirow{2}{*}{ tibia } & $\mathrm{F}$ & 2 & 3 & 1 & 1 & & 1 & & 1 \\
\hline & UM & & 2 & 2 & 1 & & & & \\
\hline \multirow{3}{*}{ calcañar } & $\mathrm{F}$ & 2 & & & 2 & & & & \\
\hline & UM & 1 & 1 & 2 & & & & & \\
\hline & I & 1 & & 1 & & & & & \\
\hline astrágalo & F & 3 & 2 Ovis & & 1 & & & & \\
\hline metatarso & $\mathrm{F}$ & 7 & 4 & & & & 1 & & \\
\hline metápodo & $\mathrm{F}$ & 3 & & & 1 & 1 & & & \\
\hline falange I & $\mathrm{F}$ & 15 & 3 & & & 1 & & & \\
\hline falange II & $\mathrm{F}$ & 13 & 1 & 1 & 1 & & & & \\
\hline falange III & $\mathrm{F}$ & 3 & & & & & & & \\
\hline TOTAL NRD & & 63 & 55 & 23 & 8 & 10 & 17 & 1 & 1 \\
\hline NMI & & 4 & 2 & 1 & 1 & 1 & 2 & 1 & 1 \\
\hline
\end{tabular}

FIG. 8. Restos de mamíferos recuperados en las excavaciones de la Casa del Mitreo. Abreviaturas usadas: NRD = Número de Restos Determinados; NMI = Número Minimo de Individuos; $B=$ Bos taurus; $O / C=$ Ovis aries $e$ Capra hircus; $S=$ Sus sp.; $C E E$ = Cervus elaphus; $E Q=$ Equus sp.; $O R C=$ Oryctolagus cuniculus; $C A C=$ Capreolus capreolus; $C A M=$ Camelus sp. estado de fusión de los huesos: $F=$ epifisis fundida; $F V=$ fusión visible; $U M=$ metáfisis no fundida; $U E=$ epifisis no fundida; I = indeterminado. 
Respecto a las especies salvajes está presente el venado-Cervus elaphus-, animal de gran porte, muy frecuente en el entorno emeritense durante la época romana. A esta especie solo se han atribuido 8 huesos largos. Entre ellos se observa un metacarpo serrado. Los metápodos, a pesar de ser más estrechos que los de vaca, son también bastante largos, por eso también son apreciados para la elaboración de objetos óseos.

En relación con los cérvidos también se ha identificado 1 húmero de corzo - Capreolus capreolus-, especie más rara y difícil de cazar que el venado. Sin embargo, también ha sido localizado en otros contextos romanos, por ejemplo, en Alcáçova de Santarém (Davis, 2006) o en Francia, por ejemplo, en Deux-Sèvres (Rodet-Belarbi y Dieudonné-Glad, 2008). El húmero emeritense, además, presentaba marcas de corte confirmando el consumo de carne de esta especie.

El conejo salvaje -Oryctolagus cuniculus- está presente con 15 huesos largos y 2 mandíbulas de, al menos, dos individuos diferentes. Se trata de una especie salvaje cuyo aprovisionamiento sería fácil en las inmediaciones de Mérida.

También se han registrado 3 dientes, 1 incisivo y 2 molares o premolares de équido. El análisis de los pliegues del esmalte en la fase oclusal ha permitido identificar los molares/premolares como caballo -Equus caballus-. De igual modo, una primera falange de équido presentaba medidas compatibles con las establecidas por Davis et al. (2008). Un metápodo distal y un metacarpo proximal serrados de tamaños relativamente grandes remiten a la presencia, al menos, de un caballo. Se observa de nuevo el predominio del uso de metápodos para la producción de utensilios en hueso.

Entre los restos de fauna recuperados en esta excavación está una tibia distal serrada, posiblemente perteneciente a un camélido-Camelus sp.-. Aunque podría tratarse de un Camelus bactrianus, cuya distribución se limita a Oriente Medio, parece probable que sea un Camelus dromedarius, cuya distribución geográfica es más amplia, incluyendo Oriente Medio, pero también todo el N de África. Otros restos de camélidos ya habían sido encontrados en la cl Almendralejo de Mérida, también serrados (Morales et al., 1995) y en Conimbriga (Cardoso, 1992). Su probable procedencia era norteafricana tratándose de Camelus dromedarius.

Unos pocos huesos de cerdo, vaca y caprino presentaban marcas de carnívoros, roeduras que podrían estar en relación con la presencia de un cánido doméstico-Canis lupus familiaris- cuyos restos no han sido recuperados, pero estas marcas indirectas son claro ejemplo de su presencia en zonas de hábitats.

Los restos óseos de aves encontrados son muy reducidos. Hay 2 huesos -1 fémur y 1 tibia-tarsoque pertenecen a una perdiz roja-Alectoris rufa-, un galliforme salvaje muy frecuente en el paisaje ibérico y común en los conjuntos faunísticos del mundo romano (Detry y Arruda, 2013; Detry et al., 2014). Esta especie está representada incluso en la sigillata hispanica ${ }^{8}$ demostrando su relevancia para los romanos.

Cinco huesos pertenecen a gallina doméstica -Gallus domesticus-, una especie introducida por los fenicios (Hernández Carrasquilla, 1992) y común durante el período romano. Los huesos recogidos prueban la existencia de varios sectores de extracción, lo que podría hablar de la presencia de más de un individuo de gallinácea en el registro.

El análisis arqueofaunístico refuerza así la hipótesis de que estamos ante un espacio dedicado al artesanado del hueso, sobre todo, por la presencia de huesos de animales de mayor tamaño. En el caso de la oveja, el cerdo o el conejo, se trata sobre todo de restos de prácticas alimenticias.

\subsubsection{Las piezas en proceso de trabajo}

Entre los objetos de hueso recuperados en esta intervención y en la practicada en 1994 se encuentran piezas a medio camino entre la materia prima “en bruto" y las rematadas. Nos referimos a más de cien piezas que se distribuyen en los siguientes grupos (Fig. 9a-c):

8 Bustamante, M. y Detry, C.: "Cerâmica e animais: representaçóes zoomórficas em Terra Sigillata Hispánica”. En Moreno-García, M. y Pimenta, C.: Actas do Encontro "O Mundo Animal na Romanização da Península Ibérica" (Lisboa, 2015). Lisboa: DGPC, en prensa. 


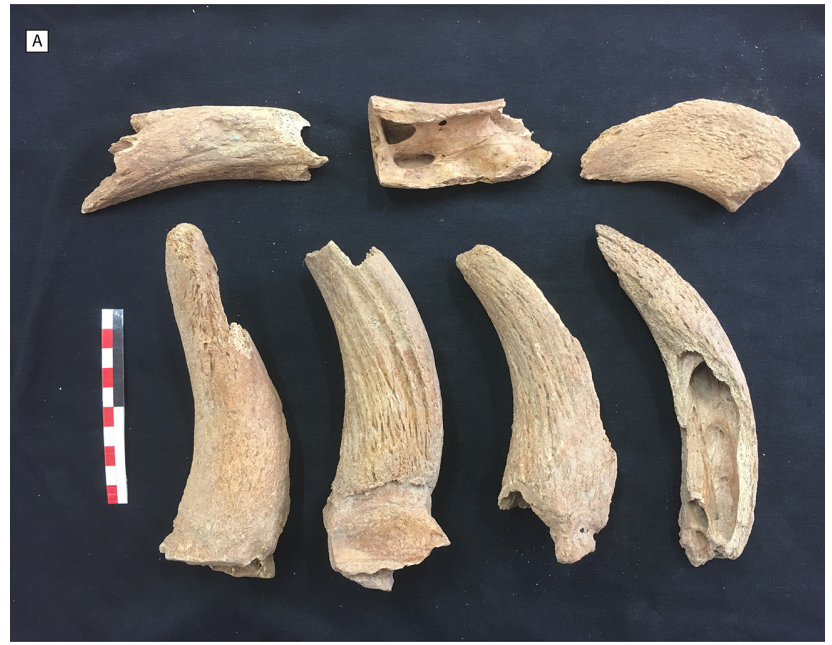

Fig. 9. Materia prima en proceso de trabajo: A) cuerno de oveja; B) restos de epifisis; C) diáfisis tras la extracción de láminas.

- Epífisis cortadas mediante un hilo-sierra de manera transversal al eje central de la pieza.

- Cuernos cortados y pretratados.

- Partes largas del hueso que han sido totalmente desprovistas de la parte esponjosa de su interior mediante cinceles o percutores, ya que no se observan huellas del hilo-sierra.

- Partes largas que, una vez desprovistas de las zonas esponjosas, comenzaron a ser trabajadas a partir de cortes limpios para favorecer la generación de pequeños vástagos en las zonas más extremas y aprovechables, prestos a ser trabajados. Por lo general, el corte se produce de manera diagonal generando un diseño a modo de punzón. Similares son los ejemplares que fueron exhumados en la taberna de Cañada la Honda de Italica (Luzón, 1975: fig. 10).

- Vástagos en proceso de limado para otorgarle la sección deseada y que, generalmente, presentan secciones angulosas.

- Esquirlas sueltas resultantes de procesos deficitarios de trabajo.

Todas las piezas, independientemente de a qué parte correspondan o la tipología que presenten, se caracterizan por haber sido tratadas externamente para obtener un acabado más deseable. De igual

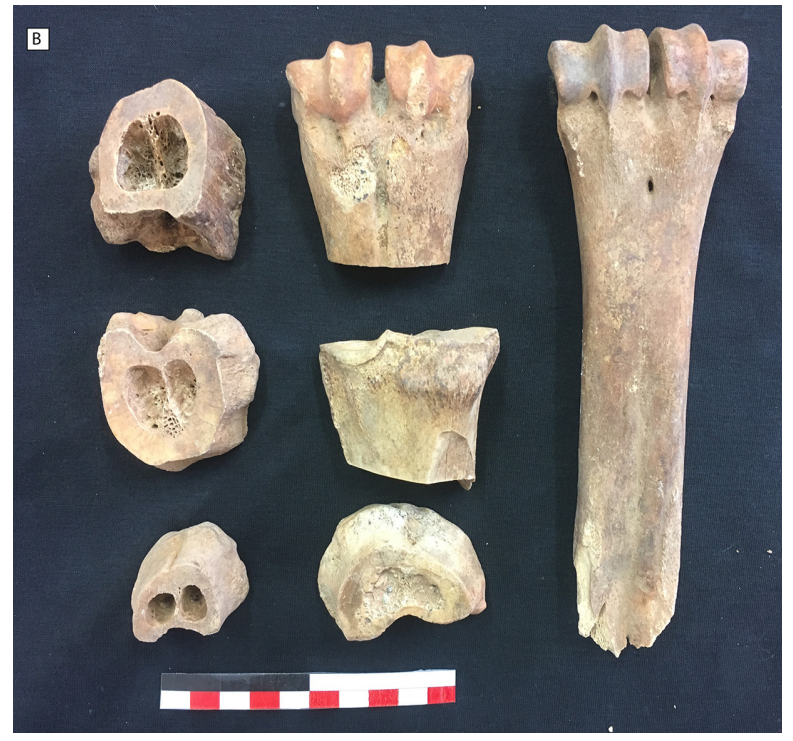

C

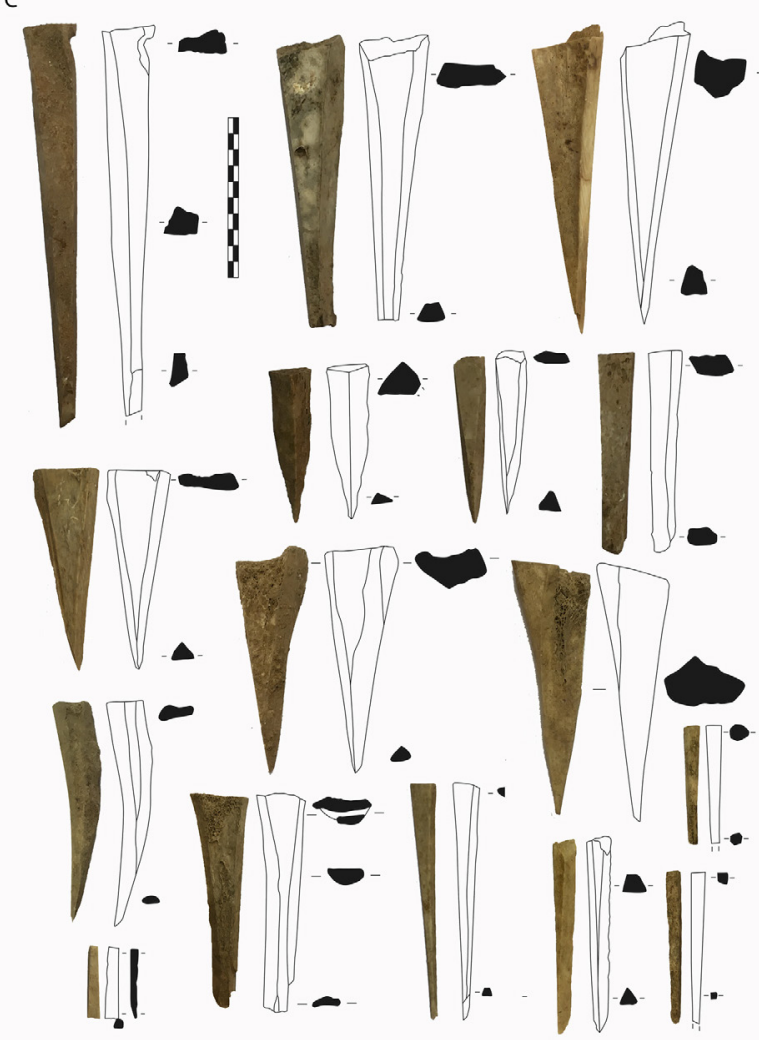

modo, se observa cómo algunas de ellas, incluso, se encuentran teñidas de verde, recurso comúnmente aplicado a este tipo de piezas, y pulidas por medio de fricción (Rascón et al., 1995: 304). Al igual que en el estudio realizado para Complutum, creemos que 
el teñido fue un recurso intencionado, quizás en un intento de emular objetos metálicos más costosos aunque ese tintado sería más difícil de mantener en el hueso con el paso del tiempo. Esta técnica de coloración se conseguía de forma simple a partir de la mezcla de vinagre con algún objeto metálico broncíneo (MacGregor, 1985: 70). Sin embargo, en nuestro estudio este fenómeno escasamente afecta a un $0,5 \%$ de las piezas analizadas y ninguna de ellas conclusa.

Desgraciadamente no se han localizado objetos que se puedan asimilar a herramientas de trabajo (Franco, 1985: 521, fig. 2a) a diferencia de lo que ocurre, por ejemplo, en Urso (Osuna) donde se encontró un elemento cilíndrico que podría estar vinculado con la producción de agujas.

\subsubsection{Piezas concluidas}

Junto con los restos antes valorados tenemos evidencias lo suficientemente sólidas para considerar que este espacio también fue una tienda. Esta hipótesis se deriva de la gran cantidad de objetos ya terminados y localizados tanto en esta estancia como en las contiguas.

A continuación vamos a valorar cuáles han sido las piezas, hasta el momento, recuperadas. Además de los grupos individualizados -tratados a continuaciónse han hallado 36 vástagos de sección circular, 91 de pequeño tamaño y sección cuadrangular más otros 40 de gran tamaño y similar sección. Debido a su fragmentación, no ha sido posible incluir estas piezas en ninguno de los grupos a los que nos referiremos a continuación; sin embargo, es necesario tenerlas en

Universidad de Salamanca cuenta a la hora de proceder a la evaluación de la instalación. Hemos podido observar que la técnica más ampliamente usada durante la fase extractiva es el serrado y, en menor medida, la percusión localizada. En relación con el proceso de elaboración que iremos detallando para cada pieza, indicamos que todas las acabadas se presentan pulidas, bien mediante el uso de alguna piedra porosa o bien mediante la fricción con cuero hasta lograr un acabado muy lustroso.

\subsubsection{Acus crinalis para aprehender}

Los alfileres, como objetos de aprensión, son los más frecuentes en el registro recuperado. De hecho, destaca la homogeneidad tipológica existente en todo el mundo romano que indica un fenómeno de transferencia de modas y modos productivos (Aguado et al., 2007: 508). Además de ser, posiblemente, las piezas más demandadas, son también las más sencillas de procesar perfilándose como los objetos más económicos elaborados en este tipo de instalaciones (Fig. 10).

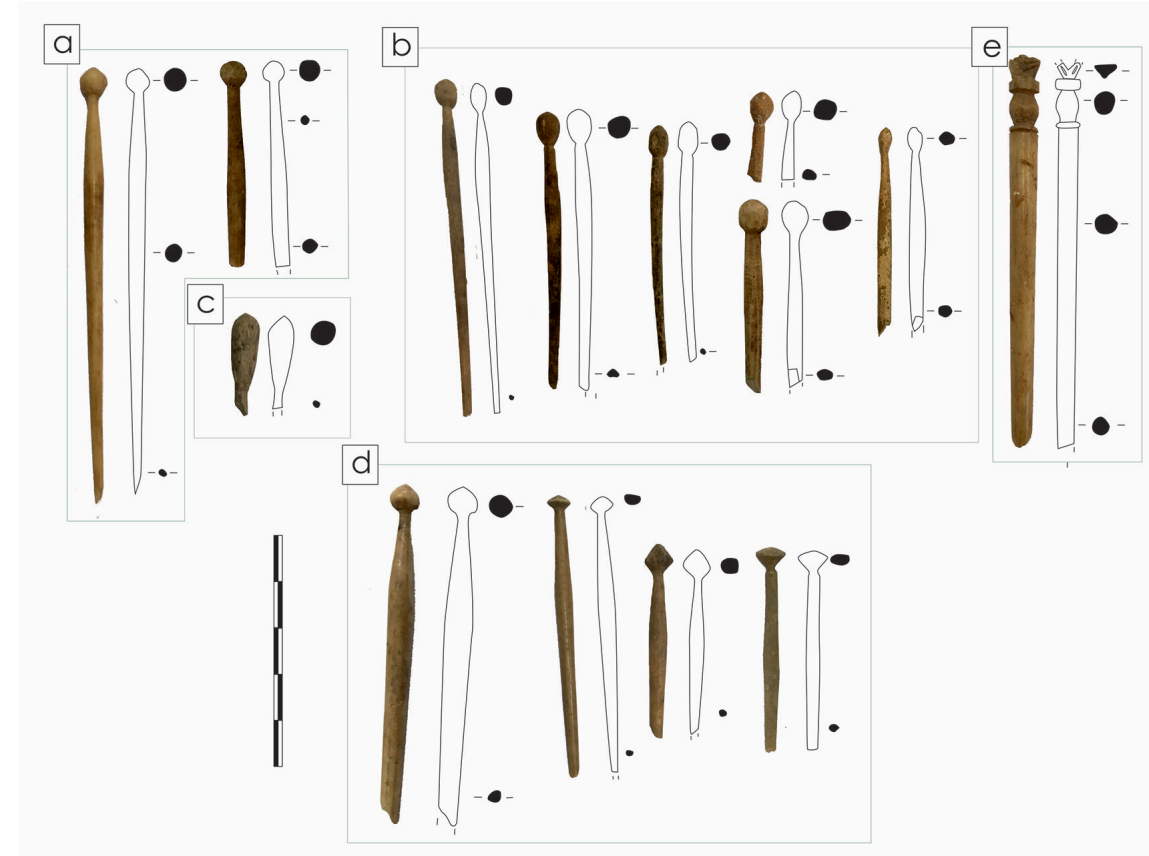

FIG. 10. Agujas de aprehensión recuperadas. 
Morfológicamente todas presentan rasgos comunes: por un lado, un fino vástago de sección fusiforme $\mathrm{y}$ acabado punzante muy preciso $\mathrm{y}$, por otro, un remate a modo de cabeza que actuara como tope y evitara su caída. Estas piezas se manufacturan a partir del desbaste de la diáfisis mediante percusión ya que no se observan líneas posibles de un hilo-sierra. Posteriormente se tornearía y/o se tallaría la zona de la cabeza del alfiler, a excepción de la que presenta un busto masculino que parece tallado a mano con ayuda de un buril. Finalmente, se procedería al pulido de la pieza.

Estas piezas se usarían bien para recoger el pelo -como indican Apuleyo (Met. II, 9 y viII, 13) o Isidoro de Sevilla (Etym. xIx, 31, 8)- o bien para sujetar prendas de vestir, aunque el término acus crinalis alude directamente al pelo. También en algunas fuentes clásicas (Ovidio, Ars Am. I, XIC, 15-17) se apuntan como posible arma por su acabado puntiagudo'.

Las diferencias existentes dentro de este grupo corresponden fundamentalmente al extremo o tope que puede aparecer realizado bien a torno o bien de forma manual, como se observa en el aristado de algunos de estos puntos ${ }^{10}$. Hemos podido diferenciar los siguientes tipos ${ }^{11}$ :

- Cabeza totalmente redondeada; son 2 ejemplares que asociamos al tipo II de Complutum o Béal xx, 7.

9 Para más datos sobre la problemática de este tipo de objetos (Rascón et al., 1995: 298 y ss.).

10 Este dato ya se apuntó en el estudio del material procedente de Complutum realizado por Rascón et al., 1995: 307.

11 Aunque el objetivo fundamental del trabajo es el estudio de la instalación en sí no queremos dejar pasar la ocasión de realizar unos apuntes tipológicos sobre las piezas localizadas. Usaremos como marco de referencia tipológico el estudio de Rascón et al., 1995. Destacamos también la revisión tipológica presentada por Rodríguez Martín (2014: 375-379); sin embargo, el hecho de no aparecer acompañado con su correspondiente cuerpo gráfico dificulta su uso como referente. Esperamos que en un futuro próximo esta propuesta se vea acompañada de un repertorio gráfico. Tampoco hay que olvidar la propuesta ofrecida para la Bética Occidental por Jiménez Melero, M.: El arreglo del cabello femenino en época romana. Evidencias arqueológicas en la Bética Occidental, tabla 1. Tesis doctoral inédita presentada en 2011 en la Univ. de Cádiz.
- Cabeza redondeada aunque parcialmente alargada; hay 6 ejemplares que corresponderían al tipo III de Complutum o Béal xx, 8.

- Cabeza a modo de bastoncillo alargado y con remate apuntado. Únicamente se ha localizado 1 fragmento. Podríamos estar ante una variante regional no documentada en otros puntos. Rodríguez Martín (1991-1992: fig. IV, 20) define este grupo como "cabeza de amapola".

- Cabeza a modo de diamante; se han hallado 4 ejemplares que están a medio camino entre los tipos Iv y v de Complutum o Béal xx, 5.

- Cabeza decorada con posible busto masculino del que únicamente se aprecian los ropajes del pecho. Un paralelo similar a esta pieza se localizó en la villa de Torre Águila, posiblemente asociable al tipo Xv de Complutum (Rodríguez Martín, 2014: fig. 8).

El tamaño ínfimo de las piezas hace que, en muchas ocasiones, las diferencias entre un grupo y otra sean mínimas.

\subsubsection{Acus vinculadas al artesanado textil y del cuero}

En este grupo se integran las agujas vinculadas con el trabajo del textil. Estas no precisan tener topes o cabezas como sí le ocurría a los objetos descritos en el punto anterior. El proceso de manufactura sería similar al de las acus anteriormente descritas, aunque creemos que en estos casos no se utilizaría el torneado (Fig. 11). Algunos investigadores han presentado algunas propuestas tipológicas, bien para el ámbito regional lusitano, como Da Ponte (1978: 133-146), o ya a escala peninsular, como Ferrer (1995: 411-415).

La característica uniforme de todas estas piezas es su sección, de tipo cuadrangular o plano. Además, algunas de ellas presentan orificios donde poder ensartar el hilo para su uso. Insertamos en este grupo algunas subulae que, aunque no presentan orificios, asociamos al trabajo de la piel. Entre los tipos identificados hay: 
- Agujas planas o punzones con extremo redondeado (Fig. 11a). Estas se encuentran desprovistas de orificio. Concretamente se adscriben aquí como subulae o punzones vinculados al laboreo de textiles o cueros de amplia dureza $^{12}$. Se han localizado tres ejemplares que corresponderían al tipo Béal A.xx, 3.

- Aguja de sección plana con extremo redondeado y orificio central de sección oblonga (Fig. 11b). Se ha recuperado un ejemplar con decoración de círculos concéntricos impresos.

- Aguja con sección plana y extremo superior plano; presenta tres orificios para insertar el hilo, el central alargado y dos circulares que lo flanquean (Fig. 11c). Sobre la función de estas aberturas no hay consenso; según algunos se usaría para pasar varios hilos al mismo tiempo (Chavanne, 1975: 103) mientras que, para otros, permitiría alternar materiales de distinto grosor (Vassy y Müller, 1922: 9). Se localizaron dos ejemplares correspondientes al tipo Béal A.XIX, 7.

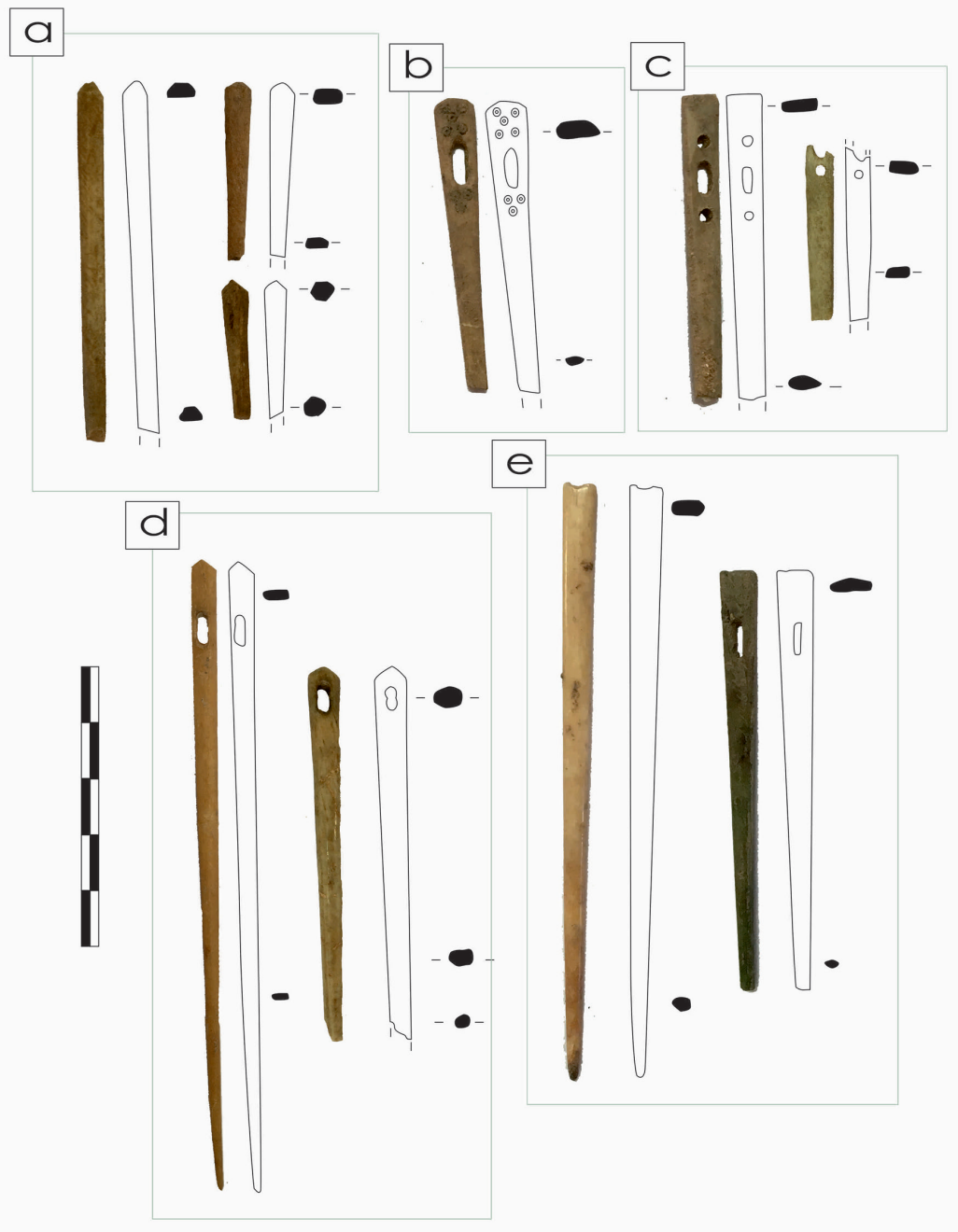

FIG. 11. Agujas asociadas al artesanado textil.

- Aguja de sección plana con extremo apuntado y orificio central alargado que se ha manufacturado a partir de dos aberturas que se cortan mutuamente; también se ha definido como perforación en ocho (Rodríguez Martín, 1992-93: 182). Se han localizado dos ejemplares correspondientes al tipo Béal A.XIX, 2 (Fig. 11d).

- Posible variante del tipo c pero únicamente presenta un orificio (Fig. 11e). En este grupo se integran dos ejemplares asignables al tipo A.XIX, 7.

12 Descartamos la posibilidad de que fueran agujas de pelo ya que la ausencia de un tope superior, a modo de cabeza, haría que se desprendieran fácilmente del objeto a sujetar, bien pelo o bien ropaje.

\subsubsection{Mangos indeterminados}

De nuevo, a partir de la epífisis ya citada, se procedería a su laminado pudiendo ser su acabado aristado o no, tal y como se advierte en las secciones de las piezas localizadas. Hemos identificado dos ejemplares: el primero podría asociarse al tipo Béal A.XVII, 1 a modo de vástago circular con extremos estrangulados e incisiones circulares y para el segundo, debido a su fractura, no podemos precisar su funcionalidad. A pesar de ello no habría que desechar la posibilidad de que estuviéramos ante un acus discriminalis (Fig. 12a). 
4.2.3.4. Desbaste o punzón

Entre el conjunto de piezas localizadas destaca una cuya funcionalidad sigue siendo objeto de debate. Nos referimos a un vástago que presenta en sus laterales huellas de la extracción de láminas y que, en el extremo superior, tiene una especie de apéndice. El hecho de que todas las caras presenten un acabado pulido podría reforzar la idea de que estamos ante un útil concluido. Sin embargo, algunos autores consideran que estaríamos ante un fragmento de materia prima en estado avanzando de gestación (Béal, 1983a: viI, 49) (Fig. 12b).

\subsubsection{Espátulas}

Presentamos dos ejemplares que asociamos a ligulae. El primero, a modo de

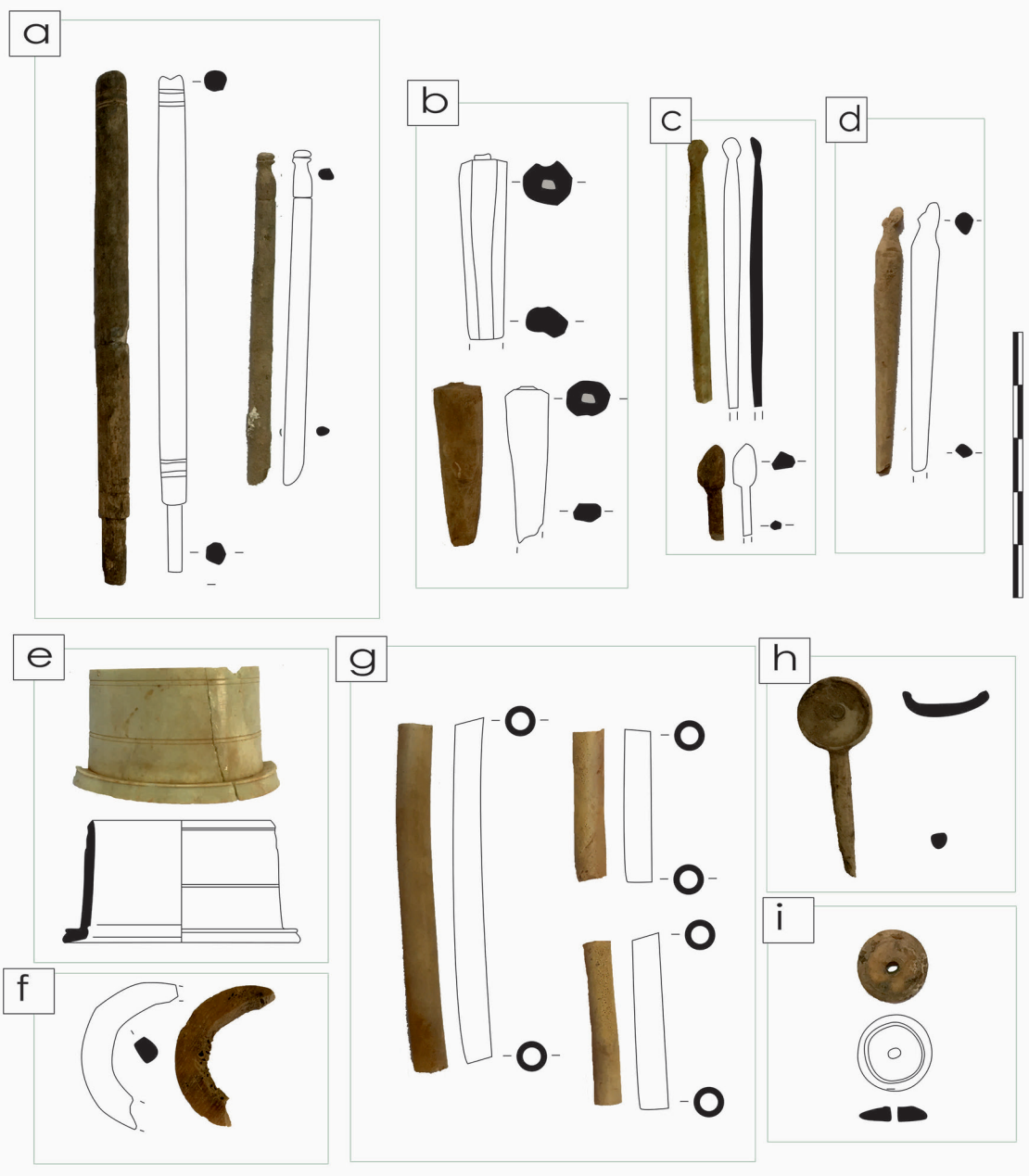

FIG. 12. Diversas piezas en hueso. cabeza de perfil indefinido, tiene un estrangulamiento en la unión entre el vástago y el extremo superior. Se podría asociar a una paleta del tipo Béal A.XxiII, 1 (Fig. 12c). Ejemplos de este tipo también se han localizado en Conimbriga (Alarcão et al., 1979: pl. xxx, 111).

El segundo presenta cabeza con sección ligeramente biselada, posiblemente usada para aplicar algún tipo de producto farmaceútico o cosmético ${ }^{13}$. Hay dos ejemplares que pueden corresponder a este tipo, Béal xx, III. Quizás estemos ante una lígula; sin embargo, no descartamos que sea un acus con la cabeza fragmentada. 100).

13 Este tipo de uso es descrito por Juvenal (Sat. II, 90-

\subsubsection{Acus discriminalis?}

Únicamente hemos localizado un ejemplar de este tipo. Son agujas con su extremo decorado, elemento que favorecería que el ungüento o líquido impregnado no se derramase. El ejemplar en cuestión presenta un estrangulamiento que podría deberse a lo indicado (Fig. 12d).

\subsubsection{Otras piezas}

Además de los grupos antes diferenciados se han localizado las piezas que ahora presentamos y para 
las que únicamente tenemos un ejemplar por tipo (Fig. 12):

- Pyxis (Fig. 12e): es un trabajo exquisito con una delgada pared y un acabado externo muy cuidado. En esta ocasión el torno sería necesario para su elaboración. Con forma cilíndrica, presenta un borde superior apuntado y abierto. En la zona inferior aparece una especie de pie a modo de uńa exterior. A lo largo de la pieza se observan incisiones decorativas. Se insertaría en el grupo de botes cilíndricos de Béal A.VI, 3 o A.VIII.

- Arandela circular de sección plana, tipo Béal A. XXXI, I (Fig. 12f).

- Abalorios tubulares posiblemente destinados al ajuar y decoración personal. Se han localizado dos ejemplares (Fig. 12g). La forma de estas piezas deriva de la propia materia prima; son huesos de aves de los que se aprovecha su morfología cilíndrica.

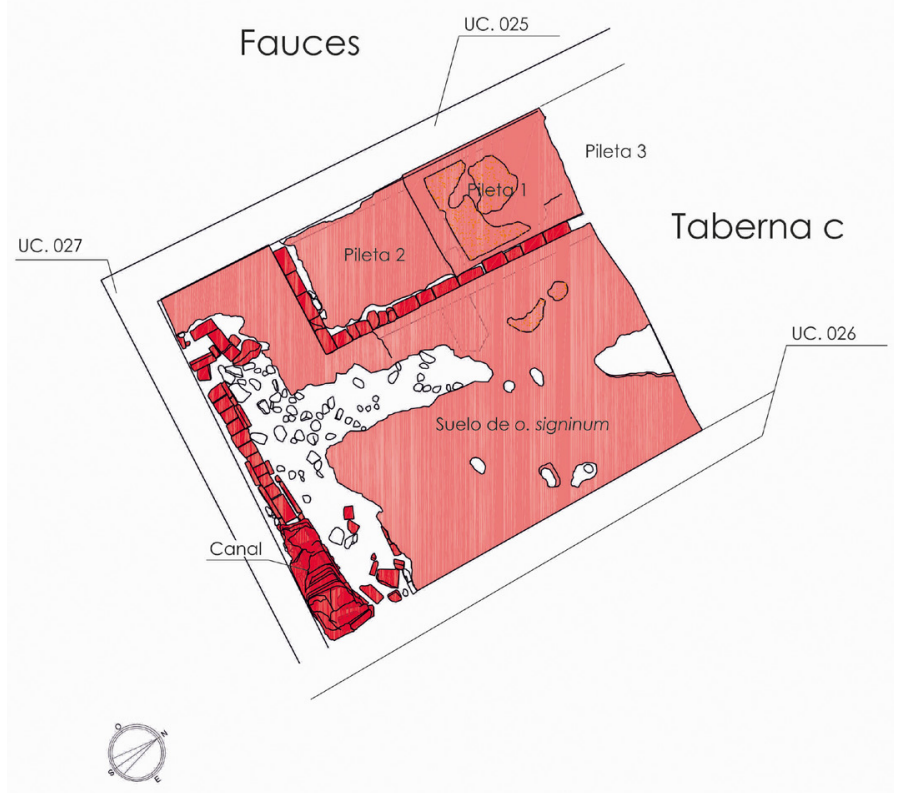

Fig. 13. Planimetría de la taberna (@) Consorcio de Mérida).

activo en la producción y consumo de dichas piezas (Fig. 13). La continua aparición de estos objetos en contextos arqueológicos ha forzado incluso el planteamiento de que esta actividad no precisaba de una mano de obra especializada y de que, incluso, podría ser una manufactura al amparo del núcleo doméstico ${ }^{14}$.

A pesar del creciente estudio de este tipo de piezas, son muy pocos los datos relativos a su artesanado, tanto en lo referido al componente humano, como a sus medios y formas de producción. Esto viene de la mano de que, hasta el momento, únicamente se han localizado restos vinculados a su actividad en contextos de vertidos, hasta seis puntos de la ciudad -en las calles Almendralejo, Pan Caliente, Morería, Seguridad Social-Zona Sur, Cuartel de Artillería y Constantino- según recoge Rodríguez Martín (2014: 368). Este mismo investigador ha hecho ya alguna referencia a la Casa del Mitreo. Lo mismo parece ocurrir en otras instalaciones tanto de corte civil, caso de las ciudades de Complutum (Rascón et al., 1995: 304 o 1998: 110) y Calagurris (Tirado, 1993), en la villa de Torre Águila (Rodríguez Martín, 1992-1993), pero también en contexto

14 Jiménez Melero, op. cit. n. 11, p. 169. 

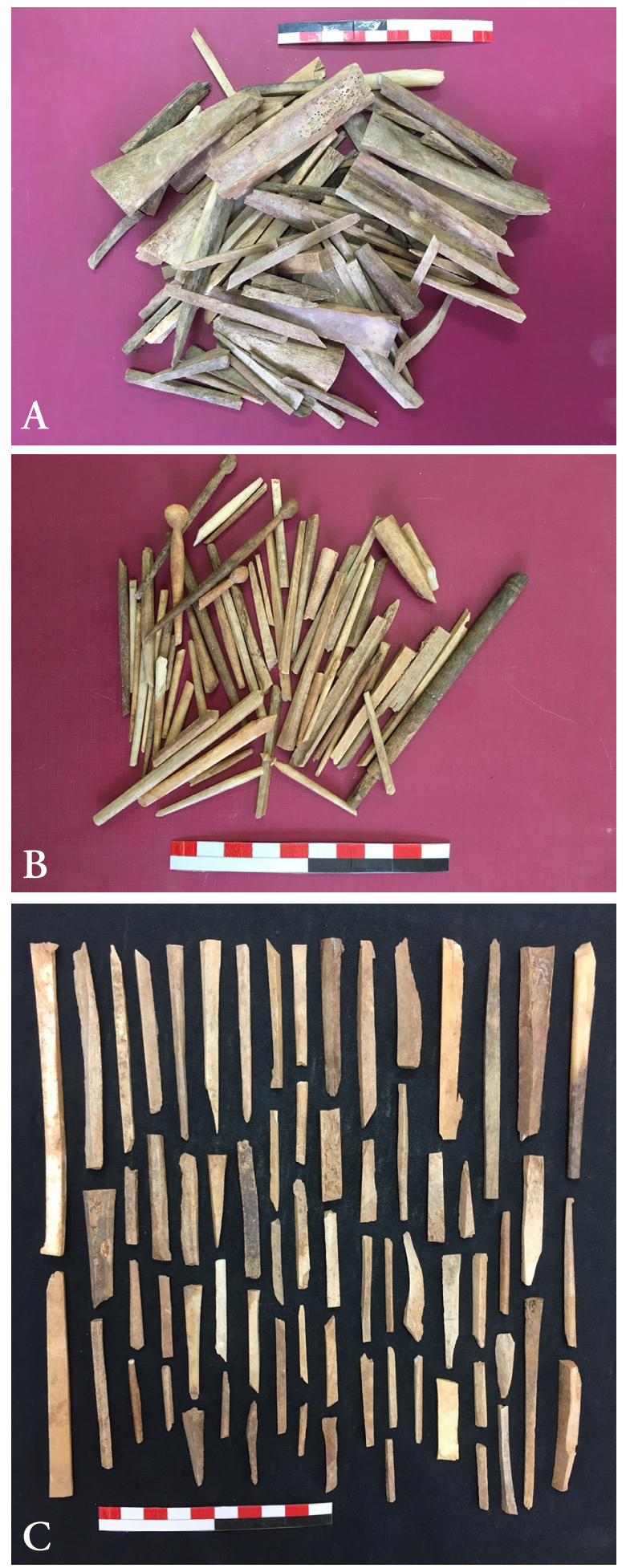

FIG. 14. Diversos objetos en proceso de trabajo: A) epifisis; B) acus en proceso de fabricación; C) deshechos varios. militar, como en Herrera de Pisuerga (Pérez González e Illarregui, 1994). Para todos ellos las evidencias se reducen a los objetos muebles, aunque no se ofrece sobre el contexto arquitectónico de estos espacios.

Este estudio quiere ahondar en el carácter artesanal y comercial de la Casa del Mitreo. Concretamente, estamos ante un taller-tienda dedicado a la producción y venta de objetos fabricados en hueso. Esto se deduce de la presencia no solo de piezas acabadas, sino también de restos de la cadena operativa además de las evidencias constructivas. A tenor de lo indicado por Rodríguez Martín (2014: 361), para que podamos hablar de un taller, es necesaria la presencia de materia prima sin tratar, materia en proceso de elaboración, objetos en fase de trabajo, recortes de talla, piezas inconclusas y objetos listos para el uso. En el caso del taller de la Casa del Mitreo, además, hay que unirle las evidencias arquitectónicas que le confieren una entidad única en la Península Ibérica.

La presencia de huellas de todos los pasos de la chaîne opératoire supone una posible alternativa a la idea que se tenía de los talleres de hueso para los que se suponía que, por un lado, se produciría el preparado de la materia prima-fundamentalmente en espacios extra moenia para minimizar la polución- $y$, por otro, se trabajarían los materiales ya tratados hasta su conformación en objetos prestos a ser comercializados. Esta teoría no invalidaría, desde nuestro punto de vista, el planteamiento de Crummy (2001: 101-102) sobre posibles talleres o artesanos itinerantes encargados de la manufactura de piezas de reducido tamaño y complejidad e, incluso, el desarrollo de una actividad doméstica dedicada a la reparación específica de algunos objetos.

El taller que hemos estudiado está ubicado en una zona adecuada para la talla del hueso, ya que la polución que este trabajo implica es mínima, pero también su cercanía a una calle de tránsito favorecería la llegada de clientes. Es cierto que la Casa del Mitreo, que ahora examinamos, se encuentra fuera de la ciudad, un posicionamiento que ya han constatado Mezquíriz (2009: 194), García-Barberana y Unzu (2013) al plantear la posible localización de 
estas instalaciones en Pompaelo (Fig. 14a-c). Otros talleres identificados en la Península Ibérica también apuestan por espacios arraigados en el corazón de la ciudad, como es el caso de Los Bañales en Zaragoza (Andreu, 2013).

Según Béal (1983a: 15), para que esta industria sea próspera son necesarios los siguientes factores, todos ellos detectables en la Casa del Mitreo:

1. Disposición suficiente de materia prima; en este sentido, la ingente cantidad de restos de arqueofauna localizados es un dato positivo.

2. Desarrollo de una industria continuada $y$ próspera.

3. Precios, aunque no precisables, quizás insertos en la esfera de objetos de lujo. Sobre este punto no podemos aportar más datos; sin embargo, sí queremos apuntar que la vivienda a la que se asocia -al menos, arquitectónicamente y no sabemos si por titularidad- parece pertenecer a uno de los emeritenses más potentes lo que, sin lugar a dudas, justificaría este ambiente de lujo.

También se ha apuntado la posibilidad de que estos talleres estuvieran vinculados con otras actividades artesanales (Rodríguez Martín, 2014: 362). De hecho, para la Casa del Mitreo se ha propuesto la cohabitación con oficinas dedicadas a producción de cerámica o de vidrio. Sin embargo, a tenor de los resultados de esta intervención, que se encuentran en vías de publicación, dichas actividades parecen corresponder a etapas previas careciendo de vinculación temporal con la producción ósea, al menos, en el espacio que ahora valoramos.

Respecto a la cronología del conjunto creemos que la officina-taberna estuvo activa desde inicios del s. II y durante el III d. C. ${ }^{15}$, datación que se aleja de la idea de que la mayoría de los talleres estarían en funcionamiento entre los ss. III y iv d. C. (Rodríguez Martín, 2014: 380). Estos indicios se derivan de los restos cerámicos vinculados a cada una de las fases, así como de la lectura estratigráfica que hemos

15 Talleres asignables a dicha cronología se han documentado en otros puntos peninsulares como, por ejemplo, en Calagurris (202). extraído de la intervención realizada en el ala $\mathrm{N}$ de la domus. En este sentido, el sellado de la puerta de la otra taberna contigua se produce a inicios del s. II d. C., cronología que se desprende del análisis de la sigillata hispanica recogida en un estrato asociado al cierre del vano -Hisp. 37 con decoración de círculos concéntricos-.

Asociamos el final del complejo a los momentos iniciales del s. III d. C. ya que en los estratos que amortizan el espacio aparecen piezas de ARSW-C de la forma Hayes 50, así como por el incendio generalizado documentado en la intervención arqueológica desarrollada en 2018 aún en estudio. Este arco cronológico cerrado podría ayudar a esclarecer cronológicamente algunas de las formas presentadas para las que, tradicionalmente, se presentaba un período de datación impreciso y muy amplio (Rascón et al., 1995: fig. 6).

\section{Bibliografía}

Abad, L. (1982): La pintura romana en España. Sevilla-Alicante: Univ. de Sevilla y de Alicante.

Aguado, M.; Bango, C. y Jiménez, O. (2007): "El hueso trabajado del yacimiento del Cerro de Álvar-Fánez (Huete, Cuenca)", Caesaraugusta, 78, pp. 495-510.

Alarcão, J.; Étienne, R.; Moutinho Alarção, A. y Da Ponte, S. (1979): Fouilles de Conimbriga VII. Trouvailes diverses-Conclusions générales. Paris: E. de Boccard.

Altieri, J. (2002): "Las pinturas báquicas de la Casa del Mitreo: iconografía", Mérida. Excavaciones Arqueológicas 2000. Memoria 6, pp. 341-359.

Andreu, J. (2013): "Sobre un repertorio de objetos de hueso romanos del norte de la Tarraconense. Los Bañales de Uncastillo (Zaragoza, España)", Habis, 44, pp. 115-139.

Arce, J. (1996): "El mosaico cosmológico de Augusta Emerita y las Dionisíacas de Nono de Panópolis". En El Mosaico Cosmológico de Mérida. Eugenio García Sandoval in memoriam. Cuadernos Emeritenses, 12. Mérida: MNAR, pp. 93-115.

BÉAL, J. C. (1983a): Catalogue des objets de tabletterie $d u$ musée de la civilisation gallo-romaine de Lyon. Lyon: Univ. Jean Moulin.

BÉAL, J. C. (1983b): "Les ateliers Gallo-Romains de tabletterie à Lyon et à Vienne”, Latomus, 42, pp. 607-618. 
Blanco, A. (1978): Mosaicos romanos de Mérida. Madrid: CSIC.

Bustamante, M. y Sabio, R. (2016): "Vermutete Werkstatt für glasierte Keramik in Augusta Emerita (Mérida)”. En Actas Rei Cretariae Romanae Fautores Congress. Bonn: RCRF, pp. 751-757.

Cardoso, J. L. (1992): "Um camelídeo de Conímbriga”, Conímbriga, xxi, pp. 181-187.

Chavanne, M. J. (1975): Salamine de Chypre. Les petits objets. París, vol. vi.

Crummy, N. (2001): "Bone-working in Roman Britain: a model for itinerant craftsmen?”. En Polfer, M. (ed.): L'artisanat romain: évolutions, continuités et ruptures (Italie et provinces occidentales). Louxembourg, pp. 97-109.

Da Ponte, M. S. (1978): "Instrumentos de fiação, tecelagem e costura de Conimbriga", Conimbriga, XvII, pp. 133-146.

DAvis, S. (1992): A rapid method for recording information about mammal bones from archaeological sites. Ancient Monuments Laboratory Report, 19. London, pp. 1-14.

Davis, S. (2006): Faunal remains from Alcáçova de Santarém (Portugal). Lisboa: IPA.

Davis, S. J.; Gonçalves, M. J. y Gabriel, S. (2008): "Animal remains from a Moslem period (12th/13th century AD) lixeira (garbage dump) in Silves, Algarve, Portugal", Revista Portuguesa de Arqueologia, 11 (1), pp. 183-258.

Detry, C. y Arruda, A. M. (2013): “A fauna da Idade do Ferro e Época romana de Monte Molião (Lagos, Algarve): continuidades e rupturas na dieta alimentar”, Revista Portuguesa de Arqueologia, 15, pp. 215227.

Detry, C.; Cardoso, J. L. y Correia, V. (2014): "What did the Romans and Moslems eat in Conimbriga? The animal bones from the 1990's excavations". En Detry, C. y Dias, R. (eds.): Proceedings First Zooarchaeology Conference in Portugal. BAR, 2662. Oxford: Archaeopress, pp. 97-110.

Devauges, J. B. (1975): "Compierre, près du temple, un atelier de tabletier", Annales du Nivernais, 10-11, pp. 18-23.

Driesch, A. (1976): A guide to the measurement of animal bones from archaeological sites. Harvard, MA: Peabody Museum of Archaeology and Ethnology.

Ellis, S. P. (2000): Roman housing. London: Duckworth.

Fernández Galiano, D. (1989-1990): “Observaciones sobre el mosaico de Mérida con la Eternidad y el Cosmo", Anas, 2-3, pp. 173-182.
Fernández Galiano, D. (1996): "El gran mitreo de Mérida: Datos comprobables". En El Mosaico Cosmológico de Mérida. Eugenio García Sandoval in memoriam. Cuadernos Emeritenses, 12. Mérida, pp. 117-183.

Franco, I. (1985): "Útiles óseos romanos de Osuna (Sevilla)", Habis, 16, pp. 517-524.

García Barberana, M. y Unzu, M. (2013): “Un barrio artesanal periurbano en la ciudad romana de Pompaelo", Cuadernos de Arqueología. Univ. de Navarra, 21, pp. 219-255.

García Sandoval, E. (1969): "El mosaico cosmogónico de Mérida”, Boletín del Seminario de Estudios de Arte y Arqueología, XXXIV-XXXv, pp. 9-29.

Hernández Carrasquilla, F. (1992): "Some comments on the introduction of domestic fowl in Iberia”, Archaeofauna, 1, pp. 45-53.

Konczewska, M. (2011): "Bone, horn and antler working in medieval Wrocław". En BARON, J. y Kufel-Daikowska, B. (eds.): Written in Bones. Studies on technological and social contexts of past faunal skeletal remains. Wrocław: Univ. of Wrocław, pp. 306-311.

Krzyszkowska, O. (1990): Ivory and Related Materials. An illustrated Guide. Oxford: Classical Handbook.

Lequement, R. (1978): "Rapport préliminaire sur deux sondages effectués à Mérida”, Noticiario Arqueológico Hispánico, 5, pp. 145-166.

López Ferrer, M. (1995): “Alfileres y agujas de hueso en época romana: avance preliminar". En Actas XXII Congreso Nacional de Arqueología. Vigo, vol. 2, pp. 411-417.

Luzón, J. M. (1975): La Itálica de Adriano. Arte Hispalense. Sevilla.

Macgregor, A. (1985): Bone, antier, ivory and horn. The technology of skeletal materials since Roman period. New Jersey: Routledge.

Mezquíriz, M. A. (2009): "Producción artesanal romana: objetos de hueso encontrados en yacimientos navarros", Trabajos de Arqueología Navarra, 21, pp. 161-198.

Morales A. M.; Riquelme, J. A. y Liesau, C. (1995): "Dromedaries in Antiquity: Iberia and beyond", Antiquity, 69, pp. 368-375.

Pérez González, C. e Illarregui, E. (1994): “Un taller de útiles óseos de la Legión ini Macedónica”, Trabalhos de Antropología e Etnologia, xxxIV (4), pp. 259-267.

Quet, M. H. (1981): Le Mosaïque Cosmologique de Mérida. Paris. 
Rascón, S. (1998): "La casa privada en el ámbito complutense”. En Rascón, S. (ed.): Complutum: Roma en el interior de la Península Ibérica. Catálogo de la Exposición (Alcalá de Henares, 1998). Alcalá de Henares: MAR, pp. 107-118.

Rascón, S.; Polo, G.; Pedreira, G. y Román, P. (1995): "Contribución al conocimiento de algunas producciones en hueso de la ciudad hispanorromana de Complutum: el caso de las acus crinales", Espacio, Tiempo y Forma. Serie I. Prehistoria y Arqueología, 8, pp. 295-340.

Rijkelijkhuizen, M. (2013): "Horn and Hoof-Plastics of the Past. The Use of Horn and Hoof as Raw Materials in the Late and Post-Medieval Periods in the Netherlands". En Lang, F. (ed.): ArchaeoPlus-Schriften zur Archäologie und Archäometrie der Paris Lodron. Salzburg: Univ. Salzburg, pp. 217-226.

Rodet-Belarbi, I. y Dieudonné-Glad, N. (2008): "Os, bois de cerf et ivoire à Rom (Deux-Sèvres). Quelques éléments de réflexion sur l'approvisionnement en matière première et la distribution des objets dans l'agglomération". En Bertrand, I. (ed.): Le travail de l'os, du bois de cerf et de la corne à l'époque romaine: un artisanat en marge? Instrumentum, 34. Montagnac, pp. 145-163.
Rodríguez Martín, G. (1992-93): "Los materiales de hueso de la villa romana de Torre Águila", Anas, IV-V, pp. 181-216.

Rodríguez Martín, G. (2014): "Artesanos y talleres de hueso en la Hispania romana". En Bustamante, M. y Bernal, D. (eds.): Artífices idóneos. Artesanos, talleres y manufacturas en Hispania. Anejos de Archivo Español de Arqueología, LXXI. Mérida: Csic, pp. 355-388.

SABIO, R. (2012): Catálogo de la colección de hierros del Museo Nacional de Arte Romano. Cuadernos Emeritenses, 37. Mérida: MNAR.

Sánchez SÁnchez, G. y Nodar, R. (1999): "Reflexiones sobre las casas suburbanas en Augusta Emerita. Estudio preliminar", Mérida. Excavaciones Arqueológicas 1997. Memoria 3, pp. 367-385.

Sautot, M. C. (ed.) (1978): Le cycle de la matière. L'os. Catalogue d'exposition. Dijon.

Tirado, J. M. (1993): "Excavación en el solar de la antigua fábrica de Torres. Calahorra", Estrato, 5, pp. 48-55.

VAssy, A. y Müller, H. (1922): "Ebauches d'objets gallo-romains en os de Sainte-Colombe-les-Vienne. Rhodania”. En Congrès de Nîmes, 710. Aix-en-Provence, pp. 1-14. 
